\title{
Condiciones de vida y pobreza multidimensional en las villas del Conurbano Bonaerense: el barrio Puerta de Hierro
}

Giovanny Hernandez Tellez ${ }^{1}$, Jimena Macció ${ }^{3}$

\section{Resumen}

En este documento se presenta una caracterización de las condiciones de vida de los hogares de la Villa Puerta de Hierro, Localidad Isidro Casanova, Partido de la Matanza, Buenos Aires, Argentina. Se aplican métodos de medición de pobreza que combinan el espacio de derechos (carencias fundamentales) y el espacio de bienestar (situación económica), empleando datos primarios. En el espacio de derechos se consideran las siguientes dimensiones: educación, vivienda y servicios públicos, cobertura de servicios de salud, alimentación, seguridad social y empleo. En el espacio de bienestar se consideran los ingresos monetarios. Los resultados muestran que casi todas las familias encuestadas presentan privaciones, que llevan a más del $60 \%$ a una situación de pobreza extrema. Se presenta un análisis de los resultados con el fin de orientar la creación de políticas públicas para producir una solución verdadera en el enfrentamiento de la pobreza extrema en la que viven las personas de la villa.

Palabras clave: derechos, bienestar, pobreza multidimensional, villas

\section{Abstract}

This article describes living conditions in the Villa Puerta de Hierro, located in Isidro Casanova, La Matanza, Province of Buenos Aires, Argentina, using methods of poverty measurement based on a human rights perspective (fundamental deficits) and a welfarist approach (households' economic situation). The dimensions of analysis in the space of human rights are education, housing and public services, health insurance, food security, work and social security. The analysis in the welfare space is based on monetary income. Results show almost every family suffers deprivations, and more than $60 \%$ of the households are extremely poor. The results are then used to make public policy recommendations for improving living conditions in the slum neighborhood.

Keywords: rights, welfare, multidimensional poverty, slums

JEL: I32, R23

DOI: https://doi.org/10.46553/ensayos.3.2.2020.p37-75

Fecha de recepción: 22/06/2020; Fecha de aceptación: 17/09/2020

\footnotetext{
${ }^{1}$ Email: giovannylux@outlook.com. Este estudio se realizó en el marco de la tesis de Maestría en Economía Aplicada de la Universidad Católica Argentina del autor, tutoreada por la coautora.

2 Universidad Católica Argentina, Departamento de Investigación "Francisco Valsecchi". Email: jmaccio@uca.edu.ar

${ }^{3}$ Los autores quisieran agradecer a Verónica Cantale, Presidenta de la Fundación CAdeNA, al Padre Pablo Ghilardini, su fundador, y a Ferdinand Van Der Berg. También quisieran agradecer los comentarios recibidos por Ann Mitchell, Carla Bonahora, Paola Bohorquéz y Hernán Ruffo sobre versiones anteriores de este documento. Los errores y omisiones en el contenido de este documento permanecen bajo entera responsabilidad de sus autores.
} 


\section{Introducción}

Relevamientos recientes calculan que más de 3 millones de personas viven en las 4.416 villas de la Argentina, de las cuales 1.726 se encuentran localizadas en el Gran Buenos Aires y 57 en la Ciudad Autónoma de Buenos Aires (RENABAP, 2018). En casi medio siglo (1962-2010) en la ciudad de Buenos Aires la cantidad de villas creció casi en un $50 \%$, y la población en villas se multiplicó por cuatro, aumentando la densidad poblacional y la relación de habitantes por vivienda (Hacienda, 2010). Las villas han venido creciendo como asentamientos urbanos no planificados surgidos de la ocupación ilegal de terrenos fiscales. Las viviendas, originalmente de materiales de desecho, son mejoradas a lo largo del tiempo por sus habitantes, quienes van incorporando servicios públicos y equipamiento a través de la acción comunitaria. Las villas, en sus orígenes espacios transitorios donde las familias se asentaban o eran localizadas por un corto periodo, resultan hogar permanente para sus habitantes, incluso por generaciones.

La pobreza en las villas es mucho más que la carencia de ingresos. La precariedad de las viviendas, el hacinamiento, la falta de acceso a servicios básicos, los déficits alimentarios, la inestabilidad de los empleos son varias de las carencias que acumulan los habitantes de estos espacios. Para su diagnóstico, se requiere emplear un enfoque multidimensional que logre captar, por un lado, todas aquellas necesidades de tipo estructural que repercuten de forma directa sobre el conjunto de derechos de los hogares, y por el otro, la capacidad que tienen los mismos de generar ingresos monetarios.

Este documento tiene como objetivo estudiar las condiciones de vida de los habitantes de la villa Puerta de Hierro, Partido de La Matanza, localidad Isidro Casanova, desde un enfoque multidimensional. Ante la escasez de información sobre esta población, se realiza un relevamiento de datos empleando un cuestionario amplio diseñado para este fin, y luego se analizan los datos recabados sobre la base de la complementación de la medición tradicional de la pobreza por ingresos mediante la consideración del espacio de los derechos para la construcción de una medida multidimensional de pobreza.

El documento se estructura como sigue. En la próxima sección, se brindan los fundamentos teóricos que respaldan el estudio de la pobreza en Puerta de Hierro desde un enfoque combinado del Espacio de Derechos y el Espacio del Bienestar. Además, se revisan brevemente algunas experiencias similares de medición de la pobreza en América Latina. En segundo lugar, se caracteriza la problemática de la pobreza territorialmente concentrada en villas y asentamientos, se pone el foco sobre el conurbano bonaerense y se presenta la historia de Puerta de Hierro. En un apartado metodológico se describen las características del relevamiento, los criterios empleados para la caracterización de las condiciones de vida en la villa, las formas de medición de la pobreza utilizadas y el diseño de la medida específica. Luego de la descripción de las características sociodemográficas de la muestra y del cálculo de la medida de pobreza multidimensional, se extraen algunas conclusiones y se proponen estrategias orientadas a la mejora de las condiciones de vida de estas familias. 


\section{Fundamentos teóricos y experiencias de medición de la pobreza multidimensional}

En esta sección se abordan los fundamentos teóricos que respaldan la medición de la pobreza desde una perspectiva multidimensional, comprendiendo las privaciones económicas, sociales, psicosociales y culturales que limitan la capacidad de desarrollo y de integración social de los hogares en situación de pobreza. Se ha definido estudiar las condiciones de vida de las personas y los hogares desde la complementación entre el espacio de Bienestar -que analiza su capacidad económica-, y el espacio de Derechos -que evalúa la imposibilidad de los hogares de acceder a ciertos derechos sociales mínimos que se consideran esenciales (ODSA, 2015; Bonfiglio, 2015; CEPAL, 2010; CONEVAL, 2010; Alkire y Foster, 2011; entre otros). Se entiende que esta es una alternativa superadora de la concepción tradicional de la pobreza como insuficiencia de ingresos. De esta manera, se logra ampliar el campo de evaluación a partir de la incorporación de distintas dimensiones que permiten complementar el método tradicional de medición de la pobreza por ingresos con la óptica de los derechos sociales (Salvia, 2016).

A continuación, se desarrollan brevemente los enfoques de Bienestar y de Derechos. Luego se mencionan algunas experiencias de medición multidimensional de la pobreza, y se desarrollan con mayor detalle aquellas sobre las que se inspira este estudio.

\section{II.1. Integración del espacio de Derechos y el espacio del Bienestar}

De acuerdo al enfoque de Bienestar, los individuos toman decisiones de consumo utilizando su conjunto de preferencias, dada una serie de dotaciones iniciales de tiempo, capital físico, financiero y humano. En este enfoque, la evaluación del bienestar de una persona obedece a sus preferencias, partiendo de las decisiones que toman los individuos de manera libre y racional para maximizar su utilidad. El enfoque de Bienestar se concentra en la disponibilidad de ingresos para adquirir bienes y servicios necesarios, partiendo de la premisa que la adquisición de estos bienes y servicios depende mayoritariamente de la capacidad monetaria que tienen los hogares, ya que la falta de ingresos reduce la capacidad que tienen estos para satisfacer un conjunto básico de necesidades. Los ingresos monetarios se utilizan, entonces, como forma de aproximarse al bienestar de esos hogares de un modo indirecto, a través de su capacidad de consumo (Salvia, 2016). De esta manera, se evalúa la capacidad de autonomía económica que tienen los hogares de transformar sus ingresos corrientes para la adquisición de unidades de consumo que satisfagan sus necesidades básicas (CONEVAL, 2009). La tipificación de los hogares con privación se hace a partir de los umbrales que ofrecen la línea de pobreza y la línea de indigencia, que permiten identificar aquellos que no cuentan con los recursos suficientes para alcanzar los bienes y servicios que cubren sus necesidades alimentarias y no alimentarias. Esta sigue siendo la forma prevalente de conceptualizar y medir la pobreza en Argentina (INDEC, 2020).

Por otro lado, el enfoque de Derechos da reconocimiento a una serie de garantías que se consideran de importancia para la plena integración social de los seres humanos, y que, por su urgencia, deben ser considerados dentro un marco jurídico nacional e 
internacional convirtiéndose en obligaciones para el Estado (OACDH, 2006). Se debe garantizar el acceso de los hogares a unos derechos sociales mínimos considerados universales y absolutos, entendiendo los derechos humanos como el "reclamo de un beneficio fundamental que debería ser disfrutado universalmente por todas las personas en todo el mundo, sobre la base de la igualdad y la no discriminación" (Vizard, 2005). El esfuerzo está orientado a velar por el cumplimiento de una serie de derechos universales que garanticen la libertad, el bienestar, y la dignidad de todas las personas en todas las sociedades a través de mecanismos jurídicos y políticos que transformen las instituciones (PNUD, 2000). Los Estados son entonces los principales responsables de hacer cumplir los derechos humanos; deben proporcionar un marco jurídico adecuado, y las instituciones que garanticen el respeto de todos los derechos. La vida humana, su calidad y dignidad, deben ser el criterio según el cual deben evaluarse los estados de las cosas, así como los arreglos económicos, políticos y sociales (Deneulin et al., 2018). Estos argumentos se basan en la premisa de que toda persona debe contar con una serie de garantías que le permitan alcanzar un estándar de vida aceptable, indispensable para su dignidad, y que le permitan tener acceso a una plena integración social.

En el espacio de los derechos se representan privaciones para los hogares obedeciendo a los parámetros fijados por la Oficina del Alto Comisionado de las Naciones Unidas para los Derechos humanos (OACDH, 2002, 2004,2009) y demás convenciones internacionales acerca de las dimensiones consideradas esenciales a la hora de caracterizar la pobreza, tales como vivienda digna, cobertura de servicios básicos, alimentación suficiente y adecuada, cobertura de servicios de salud, accesos educativos, acceso a seguridad social y empleo decente, entre otros (Deneulin et al., 2018). La privación de alguna de estas dimensiones refleja rezagos sociales que acentúan la pobreza, e imponen graves limitaciones para el desarrollo físico y social de las personas, negando la igualdad de oportunidades y "evidencian el fracaso de nuestra sociedad para abatir las enormes desigualdades sociales que en ellas persisten" (CONEVAL, 2009). Países latinoamericanos como Colombia y México, han incluido dentro de la medición de la pobreza el enfoque de derechos, buscando identificar las carencias primordiales que presente la población en aspectos esenciales para su desarrollo sostenible, y que permitan hacer la formulación efectiva de políticas públicas.

Por medio de la combinación del diagnóstico de las restricciones monetarias (espacio de Bienestar) y las restricciones de pobreza estructural (espacio de Derechos), mediante un índice único de pobreza multidimensional que permita delimitar con precisión la situación de pobreza, se busca tener un panorama más amplio de la situación social de los hogares, contemplando todos aquellos aspectos de tipo normativo que inciden en su realidad y que, de ser identificados, pueden orientar la aplicación de políticas públicas. 


\section{II.2. Revisión de las experiencias de medición multidimensional de la pobreza}

La medición multidimensional de la pobreza acumula un conjunto muy nutrido de experiencias, con enfoques y métodos variados. A nivel internacional, debe mencionarse fundamentalmente el Global Multidimensional Poverty Index (MPI). Este índice es elaborado por el Oxford Poverty and Human Development Initiative (OPHI $\left.{ }^{4}\right)$ de la Universidad de Oxford, Reino Unido, sobre la base del Enfoque de las Capacidades de Amartya Sen. El MPI se mide con regularidad para varios países del mundo, y su elaboración es liderada por Sabina Alkire, una de las autoras del método más difundido de medición de pobreza multidimensional, el método Alkire-Foster (2009). Recientemente se presentan los resultados en alianza con el PNUD (OPHIPNUD, 2020). El Enfoque Consensual para la medición de la pobreza multidimensional, inspirado en Townsend y originado en la Universidad de Bristol, Reino Unido hace más de 30 años, también tiene recepción internacional, aunque no tan amplia como el anterior. Entre los organismos internacionales que han encarado la medición de la pobreza multidimensional se destaca UNICEF, que aplica el método Multiple Overlapping Deprivation Analysis (MODA) (UNICEF, 2018, entre otros).

En América Latina hay al menos 9 países que ya han incorporado mediciones oficiales de pobreza multidimensional ${ }^{5}$. Dos países pioneros fueron México, cuya experiencia se comenta debajo en mayor detalle debido a la afinidad con el método elegido para este estudio, y Colombia ${ }^{6}$ (Departamento Nacional de Planeación República de Colombia, 2011). Chile (Ministerio de Desarrollo Social, 2015) también está entre los primeros países latinoamericanos en tomar en cuenta las medidas de pobreza multidimensional, incorporando dimensiones relevantes en su encuesta a hogares de cobertura nacional (CASEN). El Salvador ha realizado una aplicación más reciente, que se destaca por su diseño basado en un trabajo participativo con la población vulnerable, gestionada a través de organizaciones de la sociedad civil (DIGESTYC, 2018). Si bien Brasil no presenta como país una tendencia a la incorporación de este tipo de medidas, el estado brasilero de Minas Gerais se destaca por haber incorporado una medida multidimensional de pobreza local (PNUD-Polis, 2014). Ecuador (INEC, 2017), Costa Rica (INEC, 2015), Panamá (MEF, 2017), República Dominicana (SIUBEN, 2017), Guatemala (Ministerio de Desarrollo Social, 2019) son otros países que han incorporado medidas multidimensionales; algunos de ellos con la orientación del OPHI. La Comisión Económica para América Latina y el Caribe (CEPAL) también ha estudiado la pobreza multidimensional, sobre la base de la tradicional medida de necesidades básicas insatisfechas (CEPAL, 2013; CEPAL, 2014). Asimismo, ha promovido

\footnotetext{
4 Este instituto gestiona desde 2013 la Multidimensional Poverty Peer Network (Red de Pobreza Multidimensional), que agrupa 50 países que han desarrollado mediciones de pobreza multidimensional, y un conjunto de instituciones vinculadas. Puede consultarse su sitio en español en: https://mppn.org/es/nosotros/mppn/

5 Un excelente resumen de las dimensiones e indicadores considerados en las principales experiencias latinoamericanas de medición multidimensional de la pobreza puede encontrarse en Zavaleta, Moreno y Santos (2018).

${ }^{6}$ Colombia ha venido implementado medidas de pobreza Multidimensional basado en el enfoque de los derechos desde el año 2010, incluyendo las dimensiones de Vivienda digna, Cobertura servicios básicos, alimentación suficiente y adecuada, Cobertura de servicios de salud, Accesos educativos y acceso a seguridad y empleo decente, a su Plan de Desarrollo Nacional, a través de lo cual, se han creado propuestas de Políticas Públicas que enfrentan la pobreza estructural de los hogares.
} 
orientación metodológica y discusión teórica sobre el tema (CEPAL, 2010; Santos, 2019; Villatoro, 2017; entre otros).

En Argentina todavía no se han realizado avances sustantivos para la incorporación de una medida de pobreza multidimensional de alcance nacional. De la misma manera que para Brasil, hay una reciente experiencia subnacional, la de la provincia de Mendoza (DEIE-UNICEF-IELDE, 2019), y también puede mencionarse la aplicación que actualmente prepara la Dirección General de Estadísticas y Censos de la Ciudad de Buenos Aires para medir la pobreza multidimensional sobre la base del método Bristol (DGEyC, 2019). En este país se destacan una gran cantidad de estudios académicos sobre la pobreza; pueden mencionarse, sin pretensión de ser exhaustivos, los siguientes estudios: Conconi, A. y Ham, A. (2007), Batistton et al. (2013), López y Safojan (2013), Paz (2014), Arévalo y Paz (2015), Santos y Villatoro (2018), y Gallardo (2020). El Observatorio de la Deuda Social Argentina, de la Universidad Católica Argentina, mide anualmente la pobreza multidimensional en este país desde el año 2004. Asimismo, es necesario mencionar que, si bien son frecuentes los diagnósticos socioeconómicos y habitacionales en las villas y asentamientos (Cravino et. al, 2008; Márquez, 2010; Defensoría, 2017; entre tantos otros), menos frecuente es la aplicación de medidas multidimensionales que puedan captar mejor la intensidad de la pobreza de sus habitantes. Entre estos estudios específicos se puede mencionar a Lépore et al. (2012), Macció y Mitchell (2018), ODSA (2017).

De las numerosas experiencias mencionadas, se desarrollan a continuación con mayor detalle la llevada a cabo en México por la CONEVAL (2009) y la aplicada en Argentina por parte del ODSA (2020, entre otros). El motivo de la selección de estas dos experiencias es que ambas llevan a cabo una integración del enfoque de bienestar y el enfoque de derechos similar a la empleada en este estudio.

La medición de la pobreza para la $\operatorname{CONEVAL}^{7}$ en México se basa en dos aspectos que destaca como primordiales a la hora de analizar la situación social de la población: "el bienestar económico, y los derechos sociales" (CONEVAL, 2009). Mediante estos dos enfoques, se identifican aspectos apremiantes en la ejecución de políticas sociales, siendo México uno de los primeros países en América Latina que aplica este tipo de enfoques en la medición de la pobreza Multidimensional. El espacio del bienestar económico de la CONEVAL plantea un umbral mínimo de ingresos que son necesarios para satisfacer las necesidades básicas de los hogares. Esta percepción de bienestar económico contempla la capacidad que tiene una persona para adquirir ciertos bienes y servicios básicos en el mercado, pero presenta como aspecto novedoso la posibilidad de adherir productos recibidos o disponibles "en especie" (bienes que no son adquiridos por medios monetarios). Otro aspecto metodológico que se resalta es la distinción de ingresos según el tamaño y edad de los integrantes del hogar, permitiendo hacer comparaciones entre los hogares que están en la línea de bienestar (y que no cuentan con el ingreso suficiente para adquirir bienes y servicios alimentarios y no alimentarios), y los que no cumplen con sus ingresos en una línea de

\footnotetext{
7 CONEVAL (Consejo Nacional de Evaluación de la Política de Desarrollo Social) es el organismo del estado mexicano encargado de establecer los lineamientos y criterios para la definición, identificación, y medición de la pobreza.
} 
bienestar mínima (por más de que destinen todos sus recursos monetarios en la compra de alimentos básicos). En el espacio de los derechos, la CONEVAL evalúa la imposibilidad de una persona de acceder a ciertos derechos sociales que obedecen a aspectos como: rezago educativo, acceso a servicios de salud, acceso a seguridad social, calidad y espacios de la vivienda, servicios básicos, y alimentación. La falta de alguno de estos indicadores demuestra una privación en el espacio de derechos sociales, considerándose pobreza multidimensional cuando una persona no tiene garantizado el ejercicio de al menos uno de sus derechos para el desarrollo social y, sus ingresos son insuficientes para adquirir los bienes y servicios que requiere para satisfacer sus necesidades.

Mediante estos criterios, el gobierno mexicano identifica la situación de pobreza en la que se encuentran los hogares, asumiendo por medio de sus leyes el compromiso de garantizar el pleno ejercicio de los derechos sociales, y de esta forma asegurar el acceso de toda la población al desarrollo social. De esta manera, la aplicación de una medición de la pobreza multidimensional permite a los hacedores de política identificar los limitantes en el desarrollo físico y social que impiden a los hogares alcanzar un pleno desarrollo, permitiendo emplear los recursos disponibles de la mejor manera posible en pos de garantizar que los programas sociales lleguen a quienes más lo necesitan.

La experiencia de medición multidimensional de la pobreza de más larga data en la Argentina es la llevada a cabo desde el año 2004 por el Observatorio de la Deuda Social Argentina de la Universidad Católica Argentina (ODSA-UCA). Por medio de estudios que caracterizan las condiciones de vida de las personas que habitan el territorio nacional y un relevamiento propio de amplia cobertura, el Observatorio de la Deuda Social Argentina hace una estimación de la pobreza urbana desde un enfoque multidimensional, empleando variables que describen dimensiones de tipo normativo fundamentadas en los derechos económicos y sociales. Tomando como guía la experiencia mexicana, el ODSA construye una medida mediante la aplicación de los conceptos del espacio del bienestar y el espacio de los derechos, donde se mide hasta qué punto un hogar es considerado pobre o vulnerable según la carencia de una serie de indicadores planteados. En el espacio del bienestar entonces, acepta la importancia que tiene para las personas la adquisición de bienes y servicios por medio de ingresos, satisfaciendo sus necesidades más apremiantes, y atiende la capacidad de compra que tienen los hogares para acceder a una canasta básica alimentaria y no alimentaria. En el espacio de derechos reconoce los aspectos que son considerados comunes a todos los seres humanos y que se convierten en obligaciones para los estados, siendo una garantía para la plena integración social de las personas (Salvia y Lépore, 2008). Bajo este enfoque, se plantean seis dimensiones (vivienda y hábitat, cobertura de servicios básicos, acceso a una alimentación suficiente y adecuada, cobertura de servicios de salud, educación, acceso a seguridad y empleo decente), las cuales combinan criterios que están asociados a la función estatal, con criterios que contemplan aspectos puramente precedidos por los ingresos de los hogares ODSA (2010-2015). 


\section{La concentración territorial de la pobreza en las villas y asentamientos precarios}

En los últimos años, las villas y asentamientos han cobrado creciente notoriedad relacionada con las políticas de urbanización de villas históricas en ubicaciones céntricas, particularmente las promovidas por el Gobierno de la Ciudad de Buenos Aires. La crisis de salud provocada por la pandemia de COVID-19 tiene como epicentro estos barrios (Lépore and Deneulin, 2020), como consecuencia de la falta de acceso a condiciones mínimas de higiene y del hacinamiento crítico.

El conurbano Bonaerense se destaca por la proliferación de estos territorios, y por la mayor precariedad de sus asentamientos, en comparación con barrios de la Ciudad Autónoma de Buenos Aires (en adelante, CABA). Varias publicaciones han alertado sobre la situación habitacional deficitaria en la ciudad y en el Conurbano Bonaerense, y sobre el aumento de la población residente en villas, asentamientos informales y en Núcleos Habitacionales Transitorios (NHT) (Salvia, 2010-2015; Lépore et al., 2012; Suarez, Mitchell y Lépore, 2014; DGEyE, 2010; Cravino et al., 2008; entre otros). Si bien la principal característica de estos territorios es una extrema precariedad en sus características habitacionales (viviendas construidas con material de descarte, sin acceso a los servicios públicos básicos -o con acceso informal en condiciones peligrosas-, hacinamiento crítico, etc.), las carencias alcanzan a todas las dimensiones relevantes de la vida de sus habitantes.

El término villa es el más comúnmente utilizado en Argentina para referirse a barrios informales ${ }^{8}$. La aparición de las primeras villas en este país data de los años treinta, como consecuencia de fuertes migraciones internas de las zonas rurales a las zonas urbanas de personas que buscan oportunidades labores y educativas dentro de una etapa de industrialización sustitutiva de importaciones (Cravino, 2008). Por su parte, el término asentamiento precario hace referencia a barrios que tienen trama urbana regular, calles trazadas y manzanas con cuadrícula tradicional, con viviendas que presentan mejoras con respecto a las que se encuentran en las villas. Se estima que los primeros asentamientos aparecieron en los Gobiernos militares de 1976-1983, como consecuencia de un proceso de desindustrialización que trajo consigo un ambiente de escepticismo económico, con altas tasas de desempleo estructural, que llevaron a la clase obrera a asentarse en lugares con bajos costos de arrendamiento o de tenencia de tierras (Cravino, 2008).

El aumento sistemático de este tipo de hábitats ha llevado a centrar la atención de instituciones del ámbito académico como el Observatorio de la Deuda Social Argentina (ODSA) y el Programa de Pobreza, Inclusión y Política Social (PIPS) ambos de la Universidad Católica Argentina, organizaciones sin ánimo de lucro como TECHO, la

\footnotetext{
8 TECHO (2016) considera que las villas pueden definirse como urbanizaciones informales que tienen un trazado irregular, a las que se accede a través de pasillos angostos, que tienen alta densidad poblacional y estructuras autoconstruidas que pueden ser de varios pisos de alto. Para identificar asentamientos informales, TECHO utiliza el criterio del "mínimo de 8 familias agrupadas o contiguas, en donde más de la mitad de la población no cuenta con título de propiedad del suelo, ni acceso regular a al menos dos de los servicios básicos: agua corriente, energía eléctrica con medidor domiciliario y/o sistema de eliminación de excretas a través de la red de alcantarillado regular" (Plataforma de Datos Abiertos de TECHO).
} 
Defensoría del Pueblo de $\mathrm{CABA}, \mathrm{ACIJ}^{9}$, y del ámbito gubernamental ${ }^{10}$ entre otras, por conocer más sobre las problemáticas de quienes habitan en estos territorios, buscando caracterizar las principales privaciones que les impiden alcanzar un nivel de vida óptimo a sus residentes. A continuación, se presenta una breve caracterización de esta problemática en sectores del Conurbano Bonaerense, comprendiendo villas y asentamientos urbanos, y se describe el barrio sobre el cual se focaliza este estudio, Puerta de Hierro.

\section{III.1. Villas y asentamientos precarios del Conurbano Bonaerense: la villa Puerta de Hierro}

De acuerdo a datos censales, el Gran Buenos Aires (GBA), compuesto por la Ciudad Autónoma y los 24 municipios del conurbano bonaerense, comprende una población estimada cercana a los 13 millones de personas (INDEC, 2010). Se trata de aproximadamente el $25 \%$ de la población total del país (Suaya y Arena, 2018). La Matanza, municipio del conurbano donde se ubica Puerta de Hierro, es el partido más extenso del conurbano bonaerense y el más poblado de la provincia de Buenos Aires (SEDRONAR, 2017). De acuerdo con los datos de RENABAP (2018), La Matanza concentra la mayor cantidad de villas y asentamientos urbanos del conurbano (129), solo superado por la Ciudad de La Plata cuando se amplía al resto del territorio. Se ha observado que la distribución de las urbanizaciones informales no es homogénea dentro del Conurbano, concentrándose la mayor cantidad de personas en la zona sur y zona oeste, y en menor medida en la zona norte (Cravino et al., 2008).

De la misma manera, las condiciones de vida en las villas y asentamientos del conurbano son muy heterogéneas. El Índice de Progreso Social del Conurbano -que mide la extensión en la que los territorios satisfacen las necesidades sociales y medioambientales de sus ciudadanos-, muestra "la existencia de realidades muy diversas dentro del Conurbano, existiendo brechas de desarrollo que se corresponden con los procesos de urbanización y la focalización de la pobreza estructural" (Suaya y Arena, 2018, p.9). El Gran Buenos Aires tiene municipios de amplias dimensiones poblacionales y territoriales; cada uno dentro de sí contiene características sociodemográficas propias que las hacen difícilmente comparables con otro tipo de hábitats, lo que exige la aplicación de indicadores que permitan encontrar particularidades de los hogares y su población.

Las villas del conurbano se caracterizan por una amplia acumulación de privaciones y déficits que deterioran las condiciones de vida de las personas que las habitan, aún más profundas que las que evidencian las villas y asentamientos de la CABA. Uno de los indicadores con mayor déficit en gran parte de los asentamientos urbanos de este tipo, es la calidad de la vivienda y el tipo de material del cual está construida (Defensorìa del Pueblo Ciudad Autonoma de Buenos Aires, 2010). El material más frecuente en las paredes de este tipo de viviendas es ladrillo, piedra, bloque u hormigón con revoque; sin embargo, también hay viviendas con materiales de chorizo,

\footnotetext{
${ }^{9}$ Asociación Civil por la Igualdad y la Justicia (https://acij.org.ar/)

10 Se destacan el Registro Nacional de Barrios Populares del Ministerio de Desarrollo Territorial y Hábitat (https://www.argentina.gob.ar/habitat/renabap) y la Plataforma Abierta Nacional del Hábitat del Ministerio del Interior, Obras Públicas y Vivienda (https://panh.mininterior.gob.ar/\#/).,
} 
cartón, palma y material de desecho. Se calcula que solo en $4.5 \%$ de los asentamientos de la zona Oeste (donde se ubica La Matanza) los residentes cuentan con acceso formal a agua corriente. En cuanto al sistema de eliminación de excretas solo el $3 \%$ de los asentamientos de la zona Oeste cuentan con red de cloacas públicas (TECHO, 2016).

Estos indicadores permiten contar con información útil al momento de analizar las características en las que habita la población en villas, y dan cuenta de la cantidad de déficits que se encuentran en este tipo de asentamientos urbanos. Para algunos "la villa o el asentamiento informal sustituye una estación de paso, siendo una etapa habitacional necesaria para aquellos sectores desarraigados, que buscan en la metrópoli nuevas oportunidades de supervivencia y mejoramiento de su calidad de vida" (TECHO, 2016).

Puerta de Hierro comparte características comunes a las villas del conurbano, pero se caracteriza particularmente por sus altos niveles de inseguridad, asociados al comercio de drogas. Esta característica, sumada a la forma triangular de su territorio, la hacen popularmente conocida como "El triángulo del paco" ${ }^{11}$. Está ubicada en el partido de La Matanza, localidad de Isidro Casanova. El barrio posee una superficie aproximada de 6.5 hectáreas, comprendidas entre la Avenida Crovara, las vías del ferrocarril Belgrano Sur y la Calle Los Andes. Está compuesta por un número aproximado de 19 manzanas, dispuestas en 14 tiras separadas por pasillos angostos que dificultan el acceso de las ambulancias o los patrulleros. Hay presencia constante de los servicios de Gendarmería desde 2016.

Puerta de Hierro nació en 1971, producto del denominado "Plan de erradicación de las villas de emergencia de la Capital Federal y del Gran Buenos Aires", llevado a cabo por el gobierno de Onganía. El plan suponía una relocalización inicial de las poblaciones en viviendas transitorias en 17 núcleos habitacionales transitorios ( 3 en CABA y 14 en el conurbano), para luego ocupar viviendas de carácter definitivo. El asentamiento denominado Crovara en ese entonces-, se originó como un NHT para los habitantes trasladados desde la villa porteña El cartón. Con el paso del tiempo, y ante el incumplimiento de su reubicación, los habitantes de la villa comenzaron a construir viviendas con recursos y esfuerzos propios, creciendo así un asentamiento precario.

Una parte importante de los habitantes actuales del barrio provienen de estas familias originarias. De esta manera, constituyen la segunda o tercera generación en nacer y crecer en el barrio, que en sus inicios se consideraba transitorio. La mayoría de los residentes manifiestan ser propietarios de la vivienda y del terreno, pero al hablar con las personas que más tiempo han habitado en la villa, se evidencia que gran parte de Puerta de Hierro son ocupantes de hecho y habitan en estas viviendas sin títulos de propiedad $^{12}$. García (2015) estudia las trayectorias habitacionales de una muestra de estas familias relocalizadas, y destaca su pérdida de autonomía, su percepción de transitoriedad extendida en el tiempo, la sensación de desarraigo reforzada por las promesas incumplidas. En su estudio se describe el deterioro progresivo de las

\footnotetext{
${ }^{11}$ Se denomina paco a la pasta base de cocaína, una sustancia altamente adictiva y particularmente dañina para la salud.

12 Sigue en pie la decisión de urbanizar Puerta de Hierro (5 de mayo de 2017)
} 
condiciones de vida en el barrio, el incremento de la inseguridad y la gradual extensión de la villa hacia terrenos lindantes al Ferrocarril General Belgrano (García, 2015).

La Secretaría de Políticas Integrales sobre Drogas de la Nación Argentina (SEDRONAR, 2017) identifica los radios censales correspondientes a la villa con el objetivo de caracterizar al barrio en aspectos referidos a la cobertura de servicios públicos (en particular, asistencia de adicciones, salud, educación, desarrollo social, etc. $)^{13}$. Los datos censales registran aproximadamente 612 viviendas y 2700 habitantes, de los cuales un 5\% son extranjeros, mayormente provenientes de Paraguay. Un $8 \%$ de la población no sabe leer ni escribir, más de la mitad alcanzó solamente el nivel primario y cerca del $20 \%$ completó el secundario. Al momento del censo, dos de cada tres personas se encontraban con empleo. El censo registra que el $80 \%$ de los hogares utilizan garrafas para cocinar, y el $75 \%$ acceden a red pública de agua. La conexión a la luz eléctrica es irregular en su mayoría. Sin embargo, en los años transcurridos desde el censo hasta este estudio, las condiciones presentan un deterioro progresivo registrado por García (2015, p.18): "El sistema de agua de red ha dejado de funcionar en buena parte de la villa desde hace muchos años. El servicio de recolección de residuos se realiza defectuosamente y los habitantes del lugar conviven con un extenso basural a cielo abierto sobre una de las Avenidas que atraviesa al barrio". Si bien hay al menos 5 líneas de colectivo que brindan servicios en zonas aledañas al barrio (SEDRONAR, 2017), las "diferentes líneas de transporte público que circulan por la Avenida no se detienen en las paradas que corresponden a Puerta de Hierro por 'motivos de inseguridad"' (García, 2015, p.18).

Muchas de las mejoras que presenta Puerta de Hierro son gracias al apoyo de organizaciones barriales y a la gestión parroquial. En el corazón de Puerta de Hierro se ubica el comedor comunitario RENACER, cuya directora es una referente para los habitantes de la zona. Otro referente es el sacerdote católico quien llegó a Puerta de Hierro con proyectos sociales y de infraestructura como la construcción de un club deportivo, una salita de primero auxilios, y un centro de rehabilitación para adultos. Estos proyectos han sido ejecutados en su mayoría por los residentes del barrio, siendo ellos mismos quienes construyen los centros y generan las mejoras. Otro tipo de trabajo que resaltan los habitantes de la villa es el realizado por el hogar de día fundación CAdeNA Santa Teresita. Se trata de un hogar que se ocupa de niños en situación de alta vulnerabilidad socioeducativa, cobijando a más de 150 chicos de Puerta de Hierro, de la villa 17 de Marzo, y la villa San Petersburgo, entre otras. Este tipo de organizaciones de la sociedad civil e iniciativas sin ánimo de lucro trabaja con familias que se encuentran inmersas en el flagelo del consumo y venta de drogas, como así también en la prostitución y el delito.

En Puerta de Hierro una de las principales actividades económicas es la venta del paco, ya que este barrio es un centro de expendio para consumidores que arriban diariamente a la estación Villegas del tren Belgrano Sur, provenientes de la capital y de sectores aledaños del conurbano, quienes en muchos de los casos se ven envueltos en

\footnotetext{
${ }^{13}$ El barrio ha sido censado en reiteradas oportunidades, pero con el objetivo concreto de la registración de cantidad de familias para su posible relocalización. En el año 2012, el municipio realizó el último censo en el cual se consultó a los habitantes sobre su deseo de permanecer en la villa, en el marco de los planes de urbanización del barrio.
} 
situaciones de riñas callejeras, en presencia de niños y transeúntes de la zona. La relevancia del barrio para SEDRONAR se comprende desde el efecto que esto genera sobre los propios habitantes de la villa, que fue registrado por García (2015, p. 19): "Puerta de Hierro es uno de los lugares [...] en donde la venta de drogas se ha convertido en los últimos años en una problemática que afecta en particular, entre otros, a los propios habitantes del barrio. Allí donde se despliega y consolida, específicamente, la venta y el consumo del paco se vuelven más complejas las relaciones sociales, se producen nuevos tipos de conflictos, aumenta el uso de la violencia y los efectos del consumo de esa droga, sobre todo en los más jóvenes, alcanzan grados de nocividad alarmantes". En este marco de inseguridad para los propios habitantes del barrio, que se agrava para personas ajenas al mismo, las condiciones del relevamiento realizado tuvieron ciertas limitaciones que se describen en el siguiente apartado.

\section{Metodología}

Hasta el momento en que fue realizado este estudio, la información acerca de las dimensiones poblacionales y las características demográficas y socioeconómicas de los habitantes de la villa Puerta de Hierro era escasa. La primera etapa del estudio requirió el diseño de un relevamiento de datos y de un cuestionario que permitiera evaluar las condiciones de vida de sus habitantes. Sobre la base de los resultados de este relevamiento se realizó la caracterización de las condiciones de vida en la villa, para luego construir una medida de pobreza multidimensional con un subconjunto de la información recabada. Este apartado se ocupa, en una primera sección, de la descripción del relevamiento; en una segunda sección se presentan los aspectos metodológicos contemplados para la caracterización sociodemográfica de la villa. Una tercera sección se encarga de las metodologías de medición de la pobreza empleadas, para finalmente en la cuarta sección describir el diseño específico de la medida multidimensional basada en la complementación del espacio de derechos y del espacio del bienestar.

\section{IV.1. Relevamiento estadístico en Puerta de Hierro}

La obtención de información primaria en la villa Puerta de Hierro requirió varias etapas: (i) diseño conceptual de la muestra; (ii) diseño del cuestionario, (iii) relevamiento de la información (aplicación de encuestas y trabajo de campo) y (iv) acondicionamiento y sistematización de la información obtenida. Los datos que se presentan aquí corresponden al estudio cuantitativo aplicado, pero se ilustran y contextualizan a partir de la información observacional registrada durante el trabajo de campo.

Debido a las limitaciones existentes en el acceso a los pobladores de la villa y a lo reducido del equipo de trabajo $^{14}$, la muestra se seleccionó de manera no probabilística.

\footnotetext{
${ }^{14}$ Este estudio fue realizado en el marco de la tesis de maestría del primer autor, quien llevó a cabo la totalidad del trabajo de campo.
} 
Se utilizó el muestreo en cadena o muestreo bola de nieve, una técnica mediante la cual se accede a una parte de la población que se conoce $y$, por medio de la sugerencia o recomendación de estos, se tiene acceso a otra parte de la población (Goodman, 1961). La selección inicial fue realizada entre las familias de los niños y niñas que asistían en el momento del relevamiento a un comedor comunitario dentro del barrio y/o a un hogar de día ubicado en sus márgenes. Después de entrevistar los primeros referentes de hogar, estos mismos sirvieron de puente para alcanzar otros hogares. Para buscar tener una mejor representación del territorio, se identificaron las 19 manzanas de la villa y se buscó tener casos pertenecientes a cada una de ellas (véase Mapa 1). Se lograron encuestar entre 1 y 5 hogares por manzana, cubriendo incluso las zonas conocidas como las de mayor peligrosidad. En ciertas manzanas ubicadas en los márgenes de la villa se lograron pocas encuestas, ya que las casas ubicadas en los extremos de la villa en su mayoría han sido demolidas y reubicadas por el gobierno municipal ${ }^{15}$.

Debido a la utilización de este método no probabilístico de selección de la muestra, deben destacarse dos limitaciones principales a los resultados de este estudio. En primer lugar, por tratarse de un muestreo no probabilístico, no es posible establecer la probabilidad que tiene cada elemento de la población de pertenecer a la muestra obtenida, ni realizar el cálculo del error de muestreo. Como consecuencia de este diseño, los resultados presentados en este documento se refieren a los hogares encuestados y no puede generalizarse al total de la villa. En segundo lugar, existe la posibilidad de que se presente un sesgo en los resultados, que pueden evidenciar mayor pobreza que el promedio por tratarse, al menos en la selección inicial, de familias que asisten a un comedor comunitario. Asimismo, puede existir una mayor proporción de familias con hijos pequeños. Sin embargo, hay evidencia de que la asistencia a comedores comunitarios es muy extensa en estos territorios ${ }^{16}$, lo cual permite suponer que este sesgo no debería ser significativo.

Al momento del relevamiento se disponía como única información la referida a los datos de un censo municipal realizado en 2010, ya mencionados en el apartado anterior. En función de las posibilidades de acceso, la aplicación de la encuesta se realizó para 50 hogares, que resultaron estar compuestos por 256 personas, abarcando un aproximado del $10 \%$ del total conocido de individuos de Puerta de Hierro. En cada hogar visitado, se escogió un referente como unidad de relevamiento, en su mayoría mujeres madres de familia, por considerarse las más aptas para informar acerca de las características de los miembros del hogar. La utilización de esta unidad de relevamiento es habitual en experiencias de relevamientos en villas (Lépore et. al (2012), Mitchell, Macció y Mariño Fages (2018); Macció (2014)). La unidad de análisis para este estudio es el hogar. El relevamiento se llevó a cabo entre los meses marzo y mayo de 2017 , de lunes a domingos ${ }^{17}$ en los horarios matutino y vespertino.

\footnotetext{
15 Se dio inicio a la urbanización en Puerta de Hierro (12 de junio de 2017).

16 Según datos del ODSA (2019), la inseguridad alimentaria total en el conurbano bonaerense alcanzaba a $27 \%$ de la población urbana, y en 2018 la mitad de los niños que vivían en hogares del denominado estrato marginal comían en comedores comunitarios (Tuñón y Poy, 2018).

17 La realización de encuestas durante los fines de semana garantizó el acceso a referentes ocupados cuyos horarios laborales los mantenían fuera del hogar entresemana.
} 
El cuestionario empleado para el relevamiento fue diseñado sobre la base de los instrumentos empleados en investigaciones similares realizadas por instituciones académicas, gubernamentales en Argentina y la región (EDSA, 2015; Olave, 2015; INDEC, 2015; INDEC, 2010). Una tercera limitación a la que se ve sujeto el análisis se origina en la imposibilidad de recabar cierta información para la totalidad de los miembros del hogar, buscando limitar la duración de cada entrevista, por razones metodológicas (mejorar la calidad del dato) y prácticas (minimizar la exposición del encuestador y de los encuestados). De esta manera, las dimensiones de salud y de protección social y empleo solo fueron relevadas para los referentes de hogar.

Figura 1: Vista aérea de Puerta de Hierro

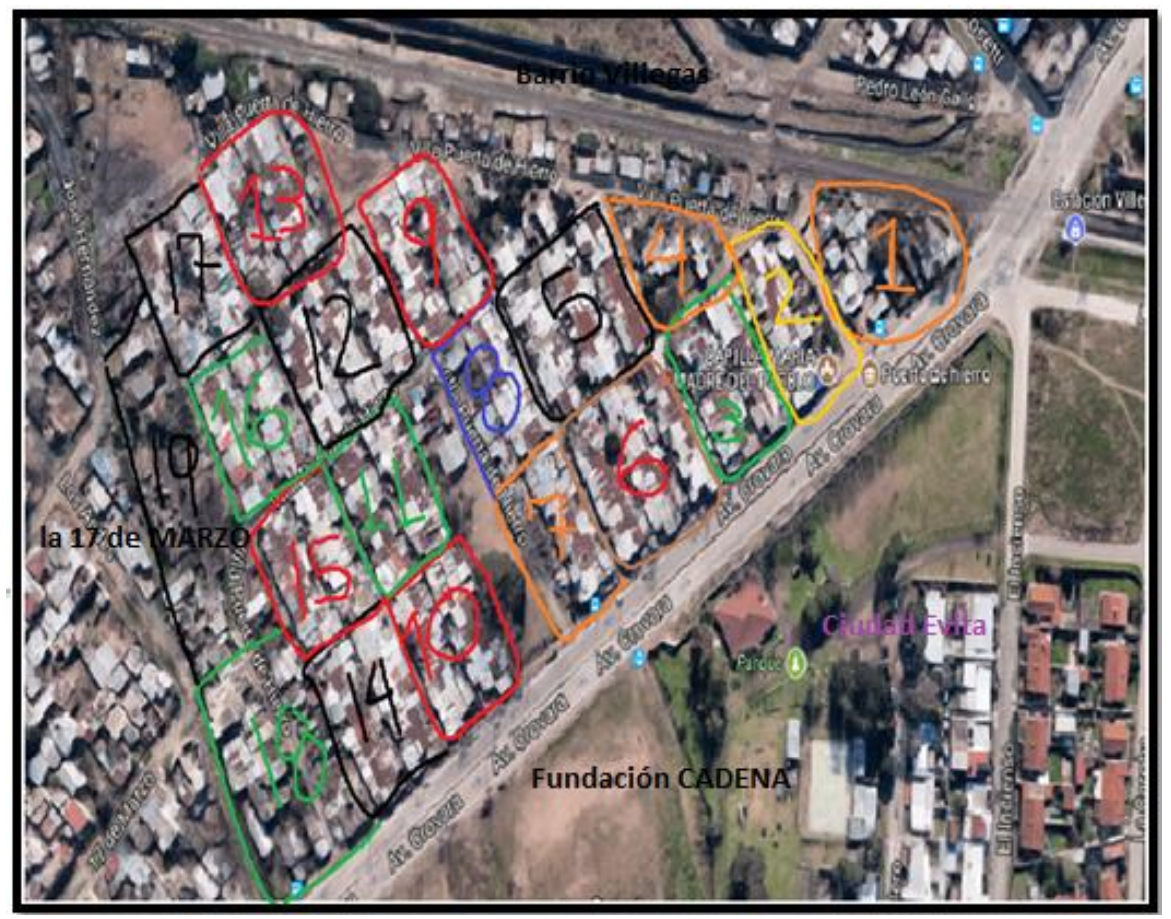

Fuente: Googlemaps (2017).

Una vez obtenida la información se procedió a sistematizar los resultados en una base de datos nutrida con la información de cada uno de los hogares. Luego se sometió la base a un proceso de consistencia para finalmente elaborar un conjunto de indicadores con el objetivo de caracterizar a la población y los hogares de la villa.

\section{IV.2. Caracterización de las condiciones de vida en Puerta de Hierro}

Sobre la base de los resultados del relevamiento descripto se buscó realizar una caracterización de las condiciones de vida de los habitantes de Puerta de Hierro. Las dimensiones analizadas se corresponden con las empleadas para el análisis de pobreza multidimensional, pero se nutren de una mayor cantidad de indicadores para distintas unidades de análisis (personas, hogares, referentes de hogar). Esta caracterización 
permite un conocimiento más amplio de la situación en la que se encuentran los habitantes del barrio.

Si bien la descripción de las condiciones de vida en Puerta de Hierro se basa principalmente en el análisis de los resultados de la encuesta, en determinadas oportunidades se ilustran estos resultados a través de información observacional obtenida al momento de realizar el trabajo de campo. Los registros observacionales redundaron en información específica de la configuración del barrio al momento de la realización de la encuesta: se tomó registro de la disposición general de las viviendas y los pasillos de acceso, se identificaron los barrios colindantes y las zonas próximas al ferrocarril. Se identificaron y registraron los pasillos donde se comercializan artículos variados, la ubicación de parques o espacios públicos de recreación, así como algunos de los pozos que los habitantes utilizan para proveerse de agua. Asimismo, se registró la presencia y la localización de instituciones en el barrio: los puestos de vigilancia policial y de Gendarmería Nacional, la ubicación de la Capilla y de los comedores comunitarios. Durante el trabajo de campo también se registraron las características generales de las viviendas a las que se visitó para la realización de las encuestas.

\section{IV.3. Métodos de identificación y agregación de la pobreza}

En este apartado se describe, en primer lugar, el método tradicional de medición de la pobreza mediante ingresos, desagregando las etapas de identificación y de agregación. Luego se presentan los principios generales para la medición de la pobreza multidimensional mediante el método de Alkire-Foster (2009).

El método de medición unidimensional basado en los ingresos es también conocido como método indirecto para la medición de la pobreza porque evalúa el bienestar a través de la capacidad monetaria de realizar consumo. Consta de dos etapas: identificación y agregación. La identificación de los pobres implica realizar una comparación entre distintos niveles de bienestar, mediante la elección de una variable cuantificable que actúe como indicador del nivel de bienestar de los hogares. El método se caracteriza por configurar una línea estableciendo un ingreso o gasto mínimo que permite mantener un nivel de vida adecuado. La línea de indigencia, establece en primer lugar una canasta básica alimentaria basada en los hábitos de consumo teniendo en cuenta criterios de frecuencia, cantidades, aporte calórico etc. Posteriormente esta canasta se convierte en calorías y se ajustan las cantidades al nivel calórico deseado obteniendo un estándar calórico. Una vez se tienen las cantidades adecuadas de alimento para el estándar calórico, se estiman los valores de los alimentos y se suman para establecer el valor de la línea de indigencia (Gonzàlez, 2011).

Luego, la construcción de la línea de pobreza (LP) por ingresos, se basa en la estimación del costo de una canasta básica de consumo de "bienes y servicios" que permite satisfacer necesidades básicas (la canasta se compone por bienes alimentarios y otros bienes). Cuando se valora esta canasta a los precios vigentes, la LP es la referencia del nivel de ingresos mínimo que un adulto equivalente ${ }^{18}$ debe tener para no

\footnotetext{
${ }^{18}$ Se calcula, a través de los requerimientos kilo-calóricos requeridos en forma mensual para un adulto, para luego ser utilizado en función del número de integrantes de los hogares.
} 
ser considerado pobre, teniendo en cuenta una canasta básica total promedio ${ }^{19}$, y calculando el costo total de todos los recursos considerados esenciales que un adulto promedio consume en un año, evaluándolo a través del gasto mínimo necesario para mantener un adecuado estándar de vida.

Finalmente, la etapa de agregación se realiza mediante la familia de índices de Foster, Greer y Thorbecke (FGT) (Foster, Greer y Thorbecke, 1986). El índice FGT considera el número de pobres permitiendo medir la incidencia, la brecha, y la severidad de la pobreza. La medida más utilizada es el índice de recuento, el cual representa por medio de la variable $\mathrm{H}$ (headcount index) la incidencia de la pobreza. Siendo $n$, el número total de personas, y $q$ el número de personas con un ingreso inferior a la línea de pobreza, $\mathrm{H}$ se obtiene como la proporción $q / n$. El índice de recuento es entonces, la proporción de personas que se encuentran bajo la línea de pobreza en relación con la población total, siendo una medida que muestra de forma sencilla el porcentaje de personas que pertenecen a hogares cuyo ingreso por equivalente adulto en un periodo determinado es inferior a la línea de pobreza (CONEVAL, 2010) ${ }^{20}$.

El método correspondiente para la identificación y agregación de la pobreza en un contexto multidimensional es el propuesto por Alkire y Foster (2009) ${ }^{21}$. Esta es una metodología que comprende una etapa de identificación (punto de corte dual) y una de agregación (se deriva de los indicadores FGT ajustados a la naturaleza multidimensional). El método AF permite analizar múltiples dimensiones de la pobreza, que los hogares experimentan simultáneamente, proponiendo una metodología útil para el diseño y seguimiento de políticas públicas, que los países pueden ejecutar en busca de la reducción de la pobreza.

En primer lugar, se identifica quién es pobre dependiendo del rango de privaciones que sufre. Una persona es identificada como privada en un indicador o dimensión, cuando el mismo cae por debajo de una determinada línea de corte. Para identificar quién es pobre multidimensional, el método de Alkire-Foster cuenta las carencias superpuestas o simultáneas que una persona o familia experimenta en diferentes indicadores; "los indicadores pueden ser ponderados por igual o pueden tener diferentes pesos" (Alkire y Foster, 2007).

Luego, son identificados como multidimensionalmente pobres las personas u hogares en los cuales, la suma ponderada de sus privaciones es mayor o igual a un umbral de pobreza. Para la selección de este umbral se puede emplear el enfoque de unión o el enfoque de intersección. El enfoque de unión identifica como pobre al hogar que está privado en al menos una de las dimensiones, presentando generalmente una

\footnotetext{
19 La estimación de la LP incluye estimar el costo de la canasta básica no alimentaria; en la canasta no alimentaria se establecen bienes y servicios para cada necesidad no alimentaria (educación, transporte, vestuario, vivienda) lo que implica establecer requisitos mínimos en cada componente.

${ }^{20}$ Los FGTs permiten medir la brecha de pobreza y la severidad de la pobreza monetaria, sobre los cuales no trabajaremos en este informe.

21 Entre los países latinoamericanos que han sido pioneros en la implementación de indicadores que capturan múltiples aspectos de la pobreza, todos los casos excepto uno, han utilizado el método AlkireFoster.
} 
predicción sobreestimada de la pobreza ${ }^{22}$. El enfoque de intersección identifica como pobre al que sufre privación en todas las dimensiones del indicador (Departamento Nacional de Planeación República de Colombia, 2011). Este enfoque puede suponer una subestimación de la pobreza. También pude seleccionarse un umbral intermedio "que en la práctica es lo más habitual, seleccionándose, por ejemplo, el equivalente a la privación en una dimensión completa" (Departamento Nacional de Planeación República de Colombia, 2011).

En el método de Alkire Foster, las medidas agregadas son las siguientes ${ }^{23}$ :

- Tasa de recuento $(\boldsymbol{H})$ o tasa de incidencia de la pobreza, está definida por $\mathrm{H}=q / n$, donde $\mathrm{q}$ es el número de personas que sufre privaciones en por lo menos $k$ dimensiones y $n$ es la población total.

- Intensidad de la pobreza (A), promedio de privaciones que sufren los multidimensionalmente pobres

- La tasa de recuento ajustada (Mo), combina información sobre el número de personas multidimensionalmente pobres, y la proporción de privaciones que sufren las personas. La medida se puede calcular como el producto de $(H \times A)$. De esta manera, el método resume las privaciones experimentadas por los pobres como una proporción de todas las posibles privaciones en la sociedad.

Uno de los objetivos del método de Alkire-Foster, es traducir los valores subyacentes de un grupo de personas en una herramienta que permita monitorear el nivel de pobreza, siendo un método que satisface una serie de propiedades o axiomas deseables. Entre ellas se destaca la posibilidad de descomponer el índice $M_{0}$ según el aporte de cada dimensión a la pobreza multidimensional ${ }^{24}$. La característica más valiosa de este método en el contexto de la medición de la pobreza multidimensional en territorios como Puerta de Hierro es la posibilidad de estudiar la acumulación de privaciones de los hogares.

\section{IV.4. Diseño de la medida de pobreza multidimensional}

Se diseñó una medida de pobreza multidimensional tomando en cuenta las experiencias recientes de medición que operacionalizan de manera combinada el espacio de Bienestar y el de Derechos (ODSA, 2019; CONEVAL, 2009). La medición de la pobreza mediante estos dos espacios brinda una noción de las limitaciones que enfrentan los hogares, estableciendo criterios diferenciados para definir la presencia o ausencia en cada uno de ellos. En el espacio de bienestar se especificó una cantidad mínima de recursos monetarios para satisfacer las necesidades básicas de los hogares por medio de una línea de pobreza y una línea de indigencia. Se construyó el índice del equivalente adulto que tiene en cuenta las necesidades calóricas de cada individuo, y

22 El enfoque unión generalmente predice un número más grande de pobres (Bourguignon y Chakravarty, 2003).

${ }^{23}$ Es posible calcular la brecha ajustada (M1) y la severidad (M2), pero estos índices quedan fuera del ámbito de este estudio.

24 M0 puede ser expresado como la suma ponderada de las tasas de privación correspondientes a cada dimensión: $M_{0}=\sum_{j=1}^{d} w_{j} h_{j}(k)$, donde $d$ es el número de dimensiones seleccionadas, $w_{j}$ es el peso relativo asignado a la dimensión $j$ y $h_{j}(k)$ es la proporción de hogares identificados como multidimensionalmente pobres y simultáneamente privados en la dimensión $j$ (Alkire et al., 2015). La contribución absoluta de la ja dimensión a $M_{0}$ es $w_{j} h_{j}(k)$. 
se utilizaron las líneas de pobreza e indigencia publicadas por INDEC (2017) para el mes de Mayo $^{25}$.

En el espacio de derechos, se evaluaron cinco dimensiones y 10 indicadores universales considerados apremiantes para la plena integración social de las personas. La elección de estas dimensiones e indicadores obedece a los criterios y a las experiencias de trabajos similares realizados por la CONEVAL México, y por el Observatorio de la Deuda Social Argentina (ODSA). Sin embargo, aunque se toman como referencia estas dos experiencias, la especificación de la medida difiere en algunos aspectos ${ }^{26,27}$. En las tablas 1 y 2 se presenta una breve descripción de las dimensiones e indicadores que se contemplan en el enfoque de derechos y de bienestar para el presente trabajo.

Para el Espacio de Derechos, se construye una medida agregada siguiendo la metodología de Alkire y Foster (2009). Se emplea una estructura de equiponderación de dimensiones, y de indicadores dentro de cada dimensión. De esta manera, cada dimensión tendrá el mismo peso (1/5), y cada indicador tendrá el mismo peso dentro de cada dimensión. La decisión de la equiponderación está fundamentada "en los principios de indivisibilidad e interdependencia de los derechos humanos, los cuales reconocen que el incumplimiento de uno de los derechos humanos vulnera el cumplimiento de los demás, y que ningún derecho humano es más importante que otro" (Departamento Nacional de Planeación República de Colombia, 2011). Para identificar a un hogar pobre en el espacio de derechos se requiere que presente privación en al menos $20 \%$ de los indicadores ponderados $(k=20 \%)^{28}$.

\footnotetext{
${ }^{25}$ La línea de pobreza para el mes de mayo es de $\$ 4.746,24$ pesos, la línea de indigencia es de $\$ 1.937,24$ pesos. Los valores corresponden a pesos argentinos y toman como referencia la región del Gran Buenos Aires.

${ }^{26}$ El grado de cohesión social es una dimensión que la CONEVAL México emplea en sus estudios de pobreza multidimensional, y está ligado a un concepto de naturaleza relacional de los individuos con su comunidad. En este caso, no se cuenta con información suficiente que permita medir adecuadamente esta dimensión, la cual no se incluye en la medida.

27 En relación con ODSA (2016), se incluye una sola dimensión de Vivienda y Servicios, en lugar de presentarse por separado. En la dimensión educativa se considera la educación del referente. Asimismo, los indicadores que se presentan para las dimensiones Salud y Trabajo y Protección Social debieron ser construidos para los referentes del hogar, debido a que la extensión del cuestionario no permitió medir determinadas dimensiones para todos los miembros del hogar.

${ }^{28}$ Se selecciona este umbral siguiendo el criterio utilizado en el Global MPI (OPHI-PNUD, 2020), entre tantas otras experiencias que ubican el umbral de pobreza multidimensional en el porcentaje equivalente al peso otorgado a cada dimensión (en este caso, 1/5 o bien, 20\%).
} 
Tabla 1: Dimensiones e indicadores contemplados en el espacio de Derechos

\begin{tabular}{|c|c|c|}
\hline Dimensión & Indicadores & Definiciones \\
\hline Educación & $\begin{array}{l}\text { Referente de hogar sin secundario } \\
\text { completo. }\end{array}$ & $\begin{array}{l}\text { El referente mayor de edad tiene nivel } \\
\text { educativo secundario incompleto o } \\
\text { inferior. }\end{array}$ \\
\hline \multirow[t]{4}{*}{$\begin{array}{l}\text { Vivienda y } \\
\text { sus } \\
\text { servicios }\end{array}$} & $\begin{array}{l}\text { El referente vive en un hogar que no } \\
\text { tiene conexión a agua corriente por } \\
\text { red pública }\end{array}$ & $\begin{array}{l}\text { En el hogar no se dispone de acceso a } \\
\text { conexión de agua corriente de red. }\end{array}$ \\
\hline & $\begin{array}{l}\text { El referente vive en un hogar que no } \\
\text { tiene conexión eléctrica }\end{array}$ & $\begin{array}{l}\text { En el hogar no se dispone de acceso a } \\
\text { conexión de red de energía eléctrica. }\end{array}$ \\
\hline & $\begin{array}{l}\text { El referente vive en un hogar que no } \\
\text { tiene conexión a red de cloacas }\end{array}$ & $\begin{array}{l}\text { En el hogar no hay conexión a red de } \\
\text { cloacas }\end{array}$ \\
\hline & $\begin{array}{l}\text { El referente vive en un hogar con } \\
\text { más de tres personas por ambiente }\end{array}$ & $\begin{array}{l}\text { El hogar registra hacinamiento (residen } \\
3 \text { o más personas por cuarto) }\end{array}$ \\
\hline Salud & $\begin{array}{l}\text { El referente no tiene cobertura } \\
\text { médica }\end{array}$ & $\begin{array}{l}\text { El referente no tiene cobertura de salud } \\
\text { y no ha podido acceder a atención } \\
\text { médica por falta de recursos } \\
\text { económicos. }\end{array}$ \\
\hline \multirow[t]{2}{*}{$\begin{array}{c}\text { Alimentació } \\
\mathbf{n}\end{array}$} & $\begin{array}{l}\text { El referente vive en un hogar donde } \\
\text { al menos una persona manifiesta } \\
\text { haber sentido hambre, dejando de } \\
\text { desayunar, almorzar, o cenar. }\end{array}$ & $\begin{array}{l}\text { Al menos un miembro del hogar tuvo } \\
\text { hambre por problemas económicos } \\
\text { durante los últimos } 12 \text { meses. }\end{array}$ \\
\hline & $\begin{array}{l}\text { El referente vive en un hogar donde } \\
\text { hubo que disminuir las porciones de } \\
\text { comida durante los últimos } 12 \\
\text { meses }\end{array}$ & $\begin{array}{l}\text { En el hogar debieron reducir de manera } \\
\text { involuntaria la porción de comida } \\
\text { durante los últimos } 12 \text { meses. }\end{array}$ \\
\hline \multirow{2}{*}{$\begin{array}{l}\text { Trabajo y } \\
\text { protección } \\
\text { social }\end{array}$} & $\begin{array}{l}\text { El referente de hogar estuvo } \\
\text { desocupado al menos una vez en los } \\
\text { últimos } 12 \text { meses }\end{array}$ & $\begin{array}{l}\text { El referente se encuentra desempleado } \\
\text { durante algún periodo en los últimos } \\
12 \text { meses. }\end{array}$ \\
\hline & $\begin{array}{l}\text { El referente tuvo un trabajo sin } \\
\text { beneficios sociales en los últimos } 12 \\
\text { meses }\end{array}$ & $\begin{array}{l}\text { El referente estuvo realizando } \\
\text { actividades labores y productivas sin } \\
\text { estar registrado en la seguridad social } \\
\text { en empleos de relación de dependencia } \\
\text { o por cuenta propia. }\end{array}$ \\
\hline
\end{tabular}

Fuente: Elaboración propia.

Tabla 2: Dimensiones e indicadores contemplados en el espacio de Bienestar

\begin{tabular}{|c|l|l|}
\hline Dimensión & \multicolumn{1}{|c|}{ Indicadores } & \multicolumn{1}{c|}{ Definiciones } \\
\hline \multirow{2}{*}{$\begin{array}{c}\text { Situación } \\
\text { económica } \\
\text { de los } \\
\text { hogares }\end{array}$} & $\begin{array}{l}\text { Referentes que viven en hogares } \\
\text { que están por debajo de la Línea de } \\
\text { pobreza }\end{array}$ & $\begin{array}{l}\text { Hogares en los que sus ingresos } \\
\text { mensuales están por debajo de la línea de } \\
\text { pobreza, pero por encima de la línea de } \\
\text { indigencia (INDEC, mayo 2017) }\end{array}$ \\
\cline { 2 - 3 } & $\begin{array}{l}\text { Referentes que viven en Hogares } \\
\text { Indigencia }\end{array}$ & $\begin{array}{l}\text { Hogares en los que sus ingresos } \\
\text { mensuales están por debajo de la línea de } \\
\text { indigencia (INDEC, mayo 2017) }\end{array}$ \\
\hline
\end{tabular}

Fuente: Elaboración propia.

La combinación del espacio de Bienestar y el espacio de Derechos, determina una matriz que permite caracterizar la pobreza multidimensional, estableciendo que la medición de la pobreza debe incluir un conjunto de indicadores asociados a funciones 
de bienestar y a derechos sociales fundamentales (ODSA, 2015). La situación de pobreza multidimensional se establece a través del criterio de intersección (registra carencia tanto en el espacio de Bienestar como en el espacio de Derechos).

Tabla 3: Matriz de Pobreza Multidimensional de los hogares consultados en Puerta de Hierro.

\begin{tabular}{|c|c|c|}
\hline \multicolumn{2}{|c|}{ Variable } & Definición \\
\hline \multirow[t]{2}{*}{$\begin{array}{l}\text { SITUACIÓN } \\
\text { DE POBREZA }\end{array}$} & POBREZA EXTREMA & $\begin{array}{l}\text { Hogares cuyos ingresos se encuentran por } \\
\text { debajo de la Línea de Indigencia y cuyos } \\
\text { referentes son pobres en el espacio de } \\
\text { derechos. }\end{array}$ \\
\hline & POBREZA & $\begin{array}{l}\text { Hogares cuyos ingresos están por debajo de } \\
\text { la Línea de pobreza y cuyos referentes son } \\
\text { pobres en el espacio de derechos. }\end{array}$ \\
\hline \multirow{2}{*}{$\begin{array}{c}\text { SITUACIÓN DE } \\
\text { VULNERABILIDAD }\end{array}$} & $\begin{array}{l}\text { VULNERABILIDAD POR } \\
\text { CARENCIAS SOCIALES }\end{array}$ & $\begin{array}{l}\text { Hogares cuyos ingresos se encuentran } \\
\text { sobre la Línea de pobreza, pero cuyos } \\
\text { referentes son pobres en el espacio de } \\
\text { derechos. }\end{array}$ \\
\hline & $\begin{array}{l}\text { VULNERABILIDAD POR } \\
\text { INGRESOS }\end{array}$ & $\begin{array}{l}\text { Hogares cuyos ingresos se encuentran bajo } \\
\text { la Línea de pobreza, pero cuyos referentes } \\
\text { no son pobres en el espacio de derechos }\end{array}$ \\
\hline $\begin{array}{c}\text { SITUACIÓN DE NO } \\
\text { POBREZA }\end{array}$ & $\begin{array}{l}\text { SIN POBREZA NI } \\
\text { VULNERABILIDAD }\end{array}$ & $\begin{array}{l}\text { Hogares cuyos ingresos se encuentran bajo } \\
\text { la Línea de pobreza, pero cuyos referentes } \\
\text { no son pobres en el espacio de derechos }\end{array}$ \\
\hline
\end{tabular}

Fuente: Elaboración propia

\section{Principales Resultados}

En esta sección se presentan los principales resultados obtenidos de las encuestas realizadas. En primer lugar, se brinda una caracterización demográfica identificando los grupos etarios, tipo y tamaño de los hogares relevados, y un perfil de los referentes de hogar. En la segunda parte se hace un análisis de cada una de las dimensiones e indicadores contemplados con los resultados obtenidos en Puerta de Hierro. Finalmente, se construye la medida de pobreza multidimensional para poder analizar la acumulación de privaciones que sufren los hogares en Puerta de Hierro.

\section{V.1. Caracterización socio-demográfica de la muestra}

Se relevó la información concerniente a 50 hogares, los cuales están compuestos por 127 mujeres y 129 hombres, haciendo un total de 256 individuos. El $70 \%$ de las personas de la muestra tiene menos de 24 años de edad; el 56\% de las personas son menores de hasta 17 años, coherentemente con la mayor juventud que presentan las poblaciones de villas y asentamientos (Macció y Lépore, 2014).

El $52 \%$ de los hogares están constituidos por 5 miembros o más, que conviven en su mayoría en hogares nucleares formados por una pareja y sus hijos (42\%). El 16\% son hogares con referente mujer y por lo menos un niño menor de 14 años. Las Tablas 4 y 
5 muestran la estructura de la población según sexo y edad, y los tipos de hogar que componen la muestra.

En cada hogar se eligió un referente quien respondió al cuestionario suministrando la información concerniente al hogar y a sus miembros (Tabla 6). Un 96\% de los referentes son mujeres, a quienes se recurrió por ser quienes más conocen sobre la dinámica del hogar. Los rangos de edad de los referentes de hogar se encuentran entre una mínima de 22 años y una máxima de 72 años, obteniendo una media de 41 años. El 58\% son personas jóvenes adultas, el $28 \%$ se encuentran entre los 24 y 34 años y el $28 \%$ en edades de 35 a 44 años; el $25 \%$ son personas adultas, y el $8 \%$ son adultas mayores.

Tabla 4: Estructura de la población según sexo y edad.

\begin{tabular}{|l|c|c|c|}
\hline \multicolumn{1}{|c|}{ Estructura de la población } & Grupos de edad & \% Mujeres & \% Varones \\
\hline Primera infancia & $0-5$ años & 13 & 19 \\
\hline Infancia & $6-12$ años & 27 & 28 \\
\hline Adolescencia & $13-17$ años & 8 & 19 \\
\hline Jóvenes & $18-24$ años & 12 & 9 \\
\hline Jóvenes Adultos & $25-44$ años & 25 & 11 \\
\hline Adultos & $45-64$ años & 12 & 2 \\
\hline Adultos mayores & 65 años o mas & 3 & 12 \\
\hline
\end{tabular}

Fuente: Elaboración propia

Tabla 5: Tipo y tamaño de los hogares que componen la muestra

TIPO DE HOGAR PARTICULAR

\begin{tabular}{|c|c|}
\hline HOGAR UNIPERSONAL & \% \\
\hline HOGAR NUCLEAR & 2 \\
\hline Hogar nuclear completo de pareja con hijos & 42 \\
\hline Hogar nuclear incompleto (sin conyugue, con hijos) & 14 \\
\hline HOGAR EXTENDIDO & \\
\hline Hogar nuclear incompleto (sin conyugue, con hijos) con otros familiares & 4 \\
\hline Hogar nuclear incompleto (sin conyugue con hijos) con otros no familiares & 4 \\
\hline Hogar nuclear completo hijos y otros familiares & 14 \\
\hline Hogar nuclear completo sin hijos y otros familiares & 4 \\
\hline
\end{tabular}

Hogar con referente mujer y con niños menores de 14 años. 16

CANTIDAD DE MIEMBROS POR HOGAR

\begin{tabular}{|l|c|}
\hline Hogares unipersonales & 2 \\
\hline Hogares con 2 miembros & 6 \\
\hline Hogares con 3 miembros & 22 \\
\hline Hogares con 4 miembros & 18 \\
\hline Hogares con 5 miembros o mas & 52 \\
\hline
\end{tabular}

Fuente: Elaboración propia 
Tabla 6: Referentes de hogar según sexo y edad

\begin{tabular}{|l|c|c|c|}
\hline & Rangos de edad & $\%$ Mujeres & $\%$ Hombres \\
\hline Jóvenes & $18-24$ años & 8 & ------ \\
\hline Jóvenes Adultos & $25-34$ años & 28 & 2 \\
\hline Jóvenes Adultos & $35-44$ años & 28 & ----- \\
\hline Adultos & $45-64$ años & 25 & ---- \\
\hline Adultos mayores & 65 años o mas & 6 & 2 \\
\hline
\end{tabular}

Fuente: Elaboración propia.

\section{V.2. Dimensiones e indicadores evaluados en Puerta de Hierro}

Esta sección presenta los principales resultados de las dimensiones e indicadores evaluados mediante el relevamiento en Puerta de Hierro. Se recorren las distintas dimensiones analizadas, presentando privaciones que se consideran como esenciales y que describen la calidad de vida de las personas, además de ser dimensiones empleadas por organismos internacionales gubernamentales, e instituciones de investigación académica a la hora de caracterizar las condiciones de vida de una población.

La primera dimensión a tomar en cuenta es la correspondiente a la vivienda y sus servicios, por tratarse de una de las que más refleja las condiciones de precariedad de los hogares. El $48 \%$ de la muestra total de hogares se encuentra en condiciones de hacinamiento (más de 2 personas por ambiente); el $24 \%$ en condiciones de hacinamiento crítico (más de 3 personas por ambiente), y se encontraron hogares donde duermen hasta 8 personas en un mismo ambiente. Un $40 \%$ no cuenta con colchón para cada miembro además del matrimonial. El material más presente en las paredes de las viviendas es el de ladrillo, piedra, y bloque con revoque, en un $72 \%$. Sin embargo, hay muchas viviendas con materiales de chapa de metal con fibrocemento. Las viviendas en Puerta de Hierro en su mayoría son de una sola planta, con muros delgados que no cuentan con aislación térmica produciéndose en invierno humedad ambiental que produce transpiración de la pared, generando hongos y grietas. Los muros tampoco cuentan con capacidad de resistencia al sonido lo que produce que se pueda escuchar de una vivienda a otra con mucha claridad ${ }^{29}$. La mayoría de los residentes manifiestan ser propietarios de la vivienda y del terreno, pero no disponen de títulos que los acrediten como propietarios.

En cuanto al acceso a servicios básicos, el $50 \%$ de los hogares no cuenta con acceso a agua por red pública y deben suplir este servicio mediante su extracción a través de pozos ubicados en ciertos puntos de la villa ${ }^{30}$. Si bien en muchos casos se paga por

\footnotetext{
${ }^{29}$ La falta de privacidad es un déficit registrado en análisis de pobreza multidimensional en asentamientos urbanos (Mitchell, Macció y Mariño Fages, 2019).

${ }^{30}$ En las condiciones actuales que plantea la pandemia por COVID-19, los altos niveles de hacinamiento que impiden el distanciamiento social y el déficit de condiciones mínimas de higiene ponen de manifiesto la alta vulnerabilidad de esta población.
} 
este servicio, el agua que obtienen no se considera potable para el consumo humano ${ }^{31}$. El $59 \%$ de los hogares cuenta con conexión a red de cloacas y el $21 \%$ hacen sus necesidades en letrinas, presentando un problema de salud pública dada la mayor exposición a los desechos y los malos olores que inundan el barrio, particularmente durante el verano. La totalidad de la villa no cuenta con acceso a gas natural por eso debe suplirse de gas en garrafas ${ }^{32}$, suponiendo un gasto adicional.

En la dimensión salud, el indicador cobertura de servicios de salud muestra que el $64 \%$ de los referentes manifiesta no tener cobertura médica y debe atenderse en hospital público o salita de atención médica primaria. Durante el relevamiento realizado en 2017, Puerta de Hierro no contaba con salita propia, por lo cual, las personas de la villa debían acudir a las salitas de la Villa 17 de marzo o la salita de Justo Villegas aproximadamente a 15 minutos de distancia en transporte público. El hospital más cercano es el Hospital Dr. Alberto Balestrini ubicado a 25 minutos aproximadamente. De los referentes de hogar consultados, el 52\% manifestó no haberse realizado algún chequeo médico en los últimos 12 meses. Gracias al apoyo de organizaciones barriales y a la gestión parroquial, durante el año 2019 se construyó una salita de primeros auxilios dentro del barrio, lo cual ayuda a mejorar las condiciones de atención de salud, al menos en casos que no revisten gravedad.

El acceso a una alimentación suficiente y adecuada es una dimensión de vital importancia (la erradicación del hambre está planteada como uno de los Objetivos de Desarrollo Sustentable) y se considera preponderante a la hora de evaluar la calidad de vida de los hogares en la villa. La seguridad alimentaria comprende el acceso en todo momento a comida suficiente para llevar una vida activa y sana, lo cual está asociado a los conceptos de estabilidad, suficiencia y variedad de los alimentos, según la $\mathrm{FAO}^{33}$ (2006). No padecer hambre es el mínimo nivel que debe estar garantizado dentro de los derechos a la alimentación; sin embargo, muchos de los referentes consultados manifestaron haber percibido hambre presentando déficit en este indicador (en este caso, el cuestionario también tuvo en cuenta la situación de otros integrantes del hogar). Se encontró que al menos un integrante del $58 \%$ de los hogares ha sentido hambre por falta de dinero para comprar alimentos. Un $63 \%$ de los hogares afirman haber tenido que disminuir la porción de comidas de los niños entre 0 y 17 años, ya que sus recursos monetarios no son suficientes para brindarles una buena alimentación. Como se mencionó anteriormente, Puerta de Hierro cuenta con dos comedores comunitarios, un comedor ubicado entre la manzana 8 y 11 conocido por los habitantes de Puerta como el "comedor de Graciela", que brinda de lunes a viernes merienda para los chicos y personas adultas de la villa, y el comedor del Hogar Santa Teresita de la Fundación CADENA, ubicado al frente de la villa cruzando la Av. Crovara, el cual brinda almuerzo y merienda para los chicos de las Villas Puerta de

\footnotetext{
31 Los pocos que tienen acceso al servicio son aquellos que viven en los márgenes de la villa y se proveen del servicio por medio de tuberías que ellos mismos construyen, cañerías en mal estado (García, 2015) y que están cercanas a la red de cloacas, aumentando la probabilidad de que la red de acueducto se mezcle con la del desagüe.

32 En promedio una garrafa de 10 kilos cuesta $\$ 87,78$, una de 12 kilos $\$ 105,34$ y una de 15 kilos $\$ 131,67$ precios moneda argentina al momento de la encuesta en 2017.

${ }^{33} \mathrm{La}$ FAO es la Organización de las Naciones Unidas para la agricultura y la alimentación, y es la organización que dicta los lineamientos en cuanto la seguridad básica alimentaria y nutricional a nivel mundial.
} 
Hierro, 17 de Marzo, Monoblocks, Villegas y zonas aledañas. Este tipo de organizaciones no gubernamentales se resaltan como un esfuerzo para mejorar las condiciones alimentarias de las personas que habitan en la zona.

La educación es el principal medio para potenciar las habilidades, conocimientos y valores éticos de las personas (CONEVAL, 2009). Es una dimensión que influye en el avance y progreso de las personas y sociedades, siendo un proceso a través del cual se transmiten conocimientos, valores, costumbres, y formas de actuar. Otro aspecto a destacar en la muestra es el bajo nivel educativo, que condiciona la posibilidad de obtener trabajos bien remunerados y dificulta la inclusión en el mercado laboral, además de ser un factor fácilmente reproducido en los jóvenes que habitan estos hogares, desalentándolos a ver la educación como una herramienta de desarrollo y progreso. El 3\% de los niños y niñas de 13 a 17 años nunca ha asistido a un establecimiento educativo, y el $21 \%$ de niñas y niños entre los 13 a 17 años asistió alguna vez, pero en la actualidad no asiste. Durante el diálogo con adolescentes durante el trabajo de campo, muchos manifestaron no sentirse interesados por terminar sus estudios secundarios, además de no contemplar siquiera la idea de ingresar a la educación superior. Otros simplemente manifestaron haber dejado de asistir a un establecimiento educativo ante la necesidad de percibir ingresos para ellos y sus familias.

En cuanto a las actividades laborales, el $28 \%$ de los referentes que se encuentran situación de desocupación, el $18 \%$ manifestó no buscar trabajo, ya que se sienten desalentados ante las barreras que les representa ingresar al mercado laboral. El $10 \%$ restante no trabaja ni desea trabajar. El $46 \%$ de los referentes de hogar se encuentran realizando alguna actividad productiva remunerada (ocupados), de los cuales, el $82 \%$ se ocupa en actividades temporales o "changas", que tienen que ver con actividades como ventas ambulantes, atender kioscos, cuidado de chicos, peluquería, etc., sin contar, aquellos que desempeñan labores asociadas al comercio de drogas y la prostitución. Por discreción con los entrevistados el cuestionario no profundizó sobre este tipo de ocupaciones y, solo se mencionan sin dar una cifra exacta. El 9\% trabajan en relación de dependencia para el sector público y el $9 \%$ con el sector privado. Este indicador es elocuente con la alta tasa de informalidad laboral que tiene la Argentina, donde se estima que más de la mitad de las personas ejercen actividades productivas no registradas, y no cuentan con la calidad plena de los derechos laborales (ODSA, 2015). Solo al $8 \%$ de los referentes ocupados se le realizan descuentos jubilatorios y manifiestan estar registrados en la seguridad social.

Cuando evaluamos la situación económica de los hogares en términos monetarios, el $88 \%$ se encuentran por debajo de la línea de pobreza, es decir, sus ingresos netos mensuales son inferiores a la línea de pobreza del período, siendo $64 \%$ pobres extremos o indigentes. En cuanto a la percepción que tienen de su situación económica, el $64 \%$ de los hogares tienen ingresos que no son suficientes para cubrir sus necesidades básicas de subsistencia (alimentación, vestuario, recreación). El 28\% afirma que les alcanza para sus necesidades, pero no para ahorrar, y el $8 \%$ manifiesta que el dinero que ganan sí es suficiente para consumo y ahorro. Otro aspecto que se identificó es la alta participación de los hogares en programas de transferencia de 
dinero por parte del gobierno mediante planes sociales, encontrando que el $56 \%$ de los hogares son beneficiarios de la Asignación Universal por Hijo (AUH) y cerca del $40 \%$ cobran la Asignación Universal por embarazo.

\section{V.3. Medición de Pobreza Multidimensional}

En la sección anterior se caracterizaron los hogares en relación a las cinco dimensiones elegidas para describir el espacio de derechos, y también en relación a la dimensión monetaria, que representa el espacio de bienestar. En esta sección, siguiendo los criterios presentados en el marco metodológico de este documento, se construye un indicador compuesto que identifica el número de carencias que acumulan los hogares desde una noción del enfoque de derechos (carencias estructurales). Luego, este indicador correspondiente al espacio de derechos se combina con el del espacio de bienestar, para dar lugar a una matriz de pobreza multidimensional similar a la de CONEVAL (2009) y ODSA (2016).

Se presenta una descripción de las 5 dimensiones y 10 indicadores que se emplean en el presente documento (vivienda, hábitat y acceso a servicios públicos, acceso a servicios de salud, acceso de los hogares a una alimentación suficiente y adecuada, educación, acceso a seguridad social y empleo decente) y se identifican los déficits de los hogares en cada uno de ellos. Se construyen dos indicadores agregados. En primer lugar, mediante el método de Alkire y Foster se calcula el indicador de incidencia de pobreza $(\mathrm{H})$ en el Espacio de Derechos. En segundo lugar, se combina este indicador con el de carencia en el Espacio de Bienestar siguiendo los lineamientos metodológicos descriptos.

\section{V.3.A. Medida agregada de pobreza en el Espacio de Derechos.}

La tabla 7 presenta los niveles de privación en los indicadores seleccionados para conformar la medida agregada de pobreza en el Espacio de Derechos, según las decisiones metodológicas presentadas. El indicador de acceso a agua corriente por red pública presenta un $50 \%$ de referentes que vive en hogares que manifiestan no tener acceso a agua por conexión a servicio público, vulnerando los lineamientos establecidos por la OMS-UNICEF, que considera en déficit aquellos hogares que no tienen acceso a este servicio, y obtienen el agua para preparar los alimentos de pozo sin bomba, agua lluvia, río, manantial, pila publica, carro tanque u otra fuente.

En cuanto a la dimensión de educación, el $46 \%$ de los referentes de hogar mayores de 25 años no cuenta con secundario completo demostrando un bajo logro educativo, que además se complementa con un $62 \%$ que, aunque se encuentran ocupados, lo hacen desarrollando actividades productivas por medio de trabajos temporales mal remunerados (un $26 \%$ de los referentes se encuentra buscando empleo activamente). Dado el bajo nivel de escolaridad que presentan los referentes de hogar, tienen una baja probabilidad de incorporarse al mercado laboral, por medio de trabajos bien remunerados y con todas las prestaciones sociales (solo el $8 \%$ de los ocupados se encuentran afiliados al sistema de seguridad social). 
Tabla 7: Porcentaje de déficit de los hogares por cada privación.

\begin{tabular}{|c|c|c|}
\hline Dimensión & Descripción del indicador & $\%$ \\
\hline \multicolumn{3}{|c|}{ ESPACIO DE DERECHOS } \\
\hline Educación & Referentes de hogar mayores de 25 años sin secundario completo & 46 \\
\hline \multirow{4}{*}{$\begin{array}{l}\text { Vivienda y } \\
\text { sus servicios }\end{array}$} & $\begin{array}{l}\text { El referente vive en un hogar que no tiene conexión a agua corriente } \\
\text { por red pública }\end{array}$ & 50 \\
\hline & El referente vive en un hogar que no tiene conexión eléctrica & 2 \\
\hline & El referente vive en un hogar que no tiene conexión a red de cloacas & 14 \\
\hline & $\begin{array}{l}\text { El referente vive en un hogar con más de tres personas por } \\
\text { ambiente }\end{array}$ & 24 \\
\hline Salud & El referente no tiene cobertura médica & 64 \\
\hline \multirow[t]{2}{*}{ Alimentación } & $\begin{array}{l}\text { El referente vive en un hogar donde al menos una persona } \\
\text { manifiesta haber sentido hambre, dejando de desayunar, almorzar, o } \\
\text { cenar. }\end{array}$ & 58 \\
\hline & $\begin{array}{l}\text { El referente vive en un hogar donde hubo que disminuir las } \\
\text { porciones de comida durante los últimos } 12 \text { meses. }\end{array}$ & 60 \\
\hline \multirow{2}{*}{$\begin{array}{l}\text { Trabajo y } \\
\text { protección } \\
\text { social }\end{array}$} & $\begin{array}{l}\text { El referente de hogar estuvo desocupado al menos una vez en los } \\
\text { últimos } 12 \text { meses. }\end{array}$ & 42 \\
\hline & $\begin{array}{l}\text { El referente tuvo un trabajo sin beneficios sociales en los últimos } 12 \\
\text { meses. }\end{array}$ & 62 \\
\hline \multicolumn{3}{|c|}{ ESPACIO DE BIENESTAR } \\
\hline Pobreza & Referentes que viven en hogares que son pobres no indigentes & 24 \\
\hline Indigencia & $\begin{array}{l}\text { Referentes que viven en Hogares que están por debajo de la línea de } \\
\text { Indigencia. }\end{array}$ & 64 \\
\hline
\end{tabular}

Fuente: Elaboración propia sobre la base de datos primarios.

En la dimensión acceso de los hogares a una alimentación suficiente y adecuada, el $60 \%$ de los referentes viven en hogares que han tenido que disminuir la porción de comidas porque no hubo suficiente dinero para comprar alimentos, y un 58\% manifiesta haber sentido hambre en los últimos 12 meses dejando de desayunar, almorzar o cenar.

Cuando se agregan los indicadores correspondientes al espacio de derechos siguiendo el método de Alkire-Foster, con las ponderaciones oportunamente presentadas y el umbral del $20 \%$ de los indicadores ponderados, encontramos que un $92 \%$ de los referentes sufre pobreza en el espacio de derechos.

\section{V.3.B. Hogares con pobreza multidimensional}

La Tabla 8 muestra una matriz de pobreza multidimensional que se compone de las definiciones de la situación de pobreza y vulnerabilidad, teniendo como criterio de evaluación las necesidades que presentan los hogares en la combinación de los espacios de derechos y de bienestar. Según esta clasificación desde un enfoque multidimensional de los hogares, se obtiene que: 
- Un $94 \%$ de los hogares sufre algún tipo de privación

- Dos tercios de los hogares relevados (64\%) están en situación de pobreza extrema considerando ambos espacios. El 22\% de los hogares se encuentran en situación de pobreza de ingresos y de derechos. Esto suma un $86 \%$ de los hogares en situación de pobreza.

- La correlación entre ambos espacios es alta en Puerta de Hierro. Sin embargo, un $6 \%$ de los hogares no hubiese sido considerado pobre si no se estudiaban las privaciones de sus referentes en el espacio de derechos, además de la pobreza monetaria. Asimismo, un $2 \%$ de los hogares pobres por ingresos, pero no en el espacio de derechos, no se hubieran identificado de emplearse solo un enfoque de derechos.

Estos resultados han sido sometidos exitosamente a análisis de robustez que permiten determinar que los resultados se mantienen, más allá de las decisiones metodológicas tomadas en relación a las ponderaciones y el umbral de pobreza elegidos para el indicador correspondiente al espacio de Derechos. Pueden consultarse estos análisis en el Anexo metodológico al final del documento.

Tabla 8: Matriz de Pobreza Multidimensional de los hogares consultados en Puerta de Hierro.

\begin{tabular}{|c|c|c|c|c|}
\hline \multicolumn{2}{|c|}{ Variable } & Definición & $\mathbf{n}$ & $\begin{array}{c}\text { \% } \\
\text { Hogares }\end{array}$ \\
\hline \multirow{2}{*}{$\begin{array}{l}\text { SITUACIÓN DE } \\
\text { POBREZA }\end{array}$} & $\begin{array}{l}\text { POBREZA } \\
\text { EXTREMA }\end{array}$ & $\begin{array}{l}\text { Hogares cuyos ingresos se encuentran por } \\
\text { debajo de la línea de Indigencia y cuyos } \\
\text { referentes son pobres en el espacio de } \\
\text { derechos. }\end{array}$ & 32 & 64 \\
\hline & POBREZA & $\begin{array}{l}\text { Hogares cuyos ingresos se encuentran por } \\
\text { debajo de la Línea de pobreza y cuyos } \\
\text { referentes son pobres en el espacio de } \\
\text { derechos. }\end{array}$ & 11 & 22 \\
\hline \multirow{2}{*}{$\begin{array}{l}\text { SITUACIÓN DE } \\
\text { VULNERABILIDAD }\end{array}$} & $\begin{array}{l}\text { VULNERABILIDAD } \\
\text { POR CARENCIAS } \\
\text { SOCIALES }\end{array}$ & $\begin{array}{l}\text { Hogares cuyos ingresos se encuentran sobre } \\
\text { la línea de pobreza, pero cuyos referentes } \\
\text { son pobres en el espacio de derechos. }\end{array}$ & 3 & 6 \\
\hline & $\begin{array}{l}\text { VULNERABILIDAD } \\
\text { POR INGRESOS }\end{array}$ & $\begin{array}{l}\text { Hogares cuyos ingresos se encuentran bajo la } \\
\text { línea de pobreza, pero cuyos referentes no } \\
\text { son pobres en el espacio de derechos. }\end{array}$ & 1 & 2 \\
\hline $\begin{array}{l}\text { SITUACIÓN DE } \\
\text { NO POBREZA }\end{array}$ & $\begin{array}{l}\text { SIN POBREZA NI } \\
\text { VULNERABILIDAD }\end{array}$ & $\begin{array}{l}\text { Hogares cuyos ingresos se encuentran sobre } \\
\text { la línea de pobreza y en donde los referentes } \\
\text { no son pobres en el espacio de derechos. }\end{array}$ & 3 & 6 \\
\hline
\end{tabular}

Fuente: Elaboración propia. Nota: $n$ corresponde a la cantidad de hogares.

Para tomar en cuenta la intensidad de las privaciones $(A)$, se puede analizar el porcentaje de indicadores del espacio de derechos en situación de privación. Se observa que los hogares en situación de pobreza extrema tienen en promedio un $58 \%$ de los indicadores del espacio de derechos en situación deficitaria (además de ser indigentes en términos monetarios). Los hogares en situación de pobreza tienen un 
promedio del $42 \%$ de sus indicadores de derechos en privación. Los hogares en vulnerabilidad por carencias sociales tienen en promedio $33 \%$ de los indicadores deficitarios, mientras que los vulnerables solo por ingresos solo el $5 \%$ de los indicadores de derechos en situación de privación. La Figura 2 presenta las medidas $H$, A y $M_{0}$ de Alkire-Foster correspondientes al Espacio de Derechos, para las dos situaciones de pobreza determinadas por la Matriz de Pobreza Multidimensional ${ }^{34}$.

Figura 2: Medidas de Alkire-Foster para el Espacio de Derechos, según situaciones de pobreza definidas por la Matriz de Pobreza Multidimensional

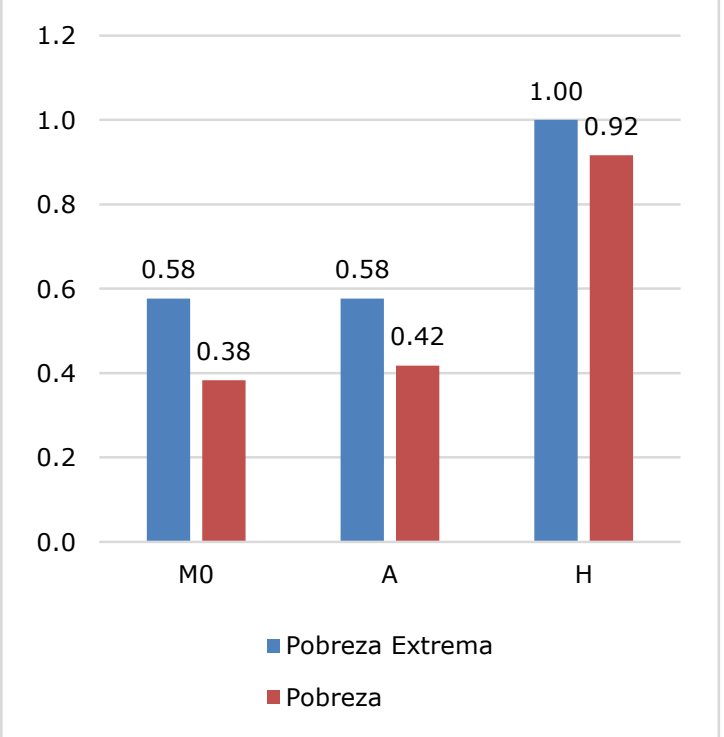

Fuente: Elaboración propia.
Figura 3: Descomposición de $\mathrm{M}_{0}$ calculado para el espacio de Derechos, según situaciones de pobreza definidas por la Matriz de Pobreza Multidimensional

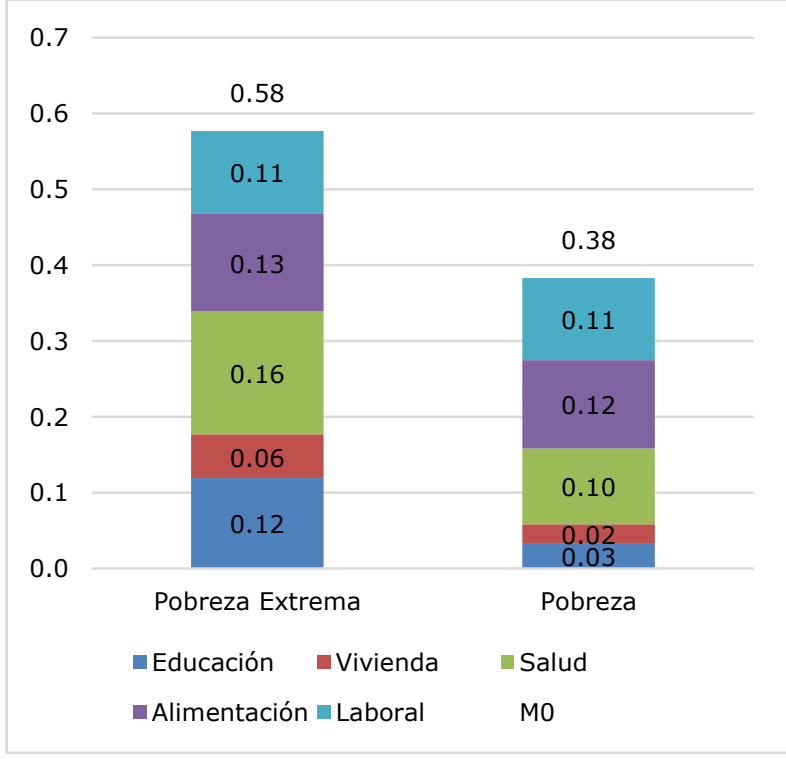

Una de las posibilidades más interesantes de las medidas multidimensionales de pobreza es la de comprender cuáles son las dimensiones que aportan en mayor medida a la pobreza multidimensional de los hogares. Sacando provecho de la propiedad de descomponibilidad por dimensiones de la medida de Alkire-Foster descripta en la sección metodológica, se presenta en la Figura 3 una desagregación de la medida de pobreza por las dimensiones del Espacio de Derechos, para las dos situaciones de pobreza combinada determinadas por la integración al Espacio de Bienestar. En lugar de expresarse de manera porcentual, se desagregan de manera tal que la suma de los valores correspondientes a cada dimensión redunda en el $M_{0}$ total. Los hogares en situación de pobreza extrema muestran el mayor índice $M_{0}$ de AlkireFoster, y las dimensiones que la conforman en mayor medida son la salud y la alimentación. Para los hogares en situación de pobreza, aunque no indigencia, el índice $\mathrm{M}_{0}$ es menor, y se observa una disminución de la relevancia de las dimensiones educativa y de vivienda, respecto de los hogares en pobreza extrema. En particular, el

\footnotetext{
34 Podrían también presentarse estos índices para los hogares en situación de Vulnerabilidad por carencias sociales. Sin embargo, se optó por no hacerlo dado que se estaría presentando la situación de tan solo 3 hogares.
} 
aporte a la medida de la pobreza multidimensional de la dimensión educativa es el que más disminuye entre los hogares pobres respecto de los que sufren pobreza extrema.

\section{Consideraciones finales y recomendaciones de políticas}

El primer paso para lograr la mejora de la vida de las personas es el reconocimiento de su forma de vida, de las privaciones que sufren a diario, la visibilización de las carencias que los aquejan. Este documento realiza un diagnóstico multidimensional de la pobreza en la villa Puerta de Hierro, mediante el relevamiento de datos primarios, identificando la pobreza como la combinación de privaciones en los espacios de Derechos y de Bienestar.

Hasta este estudio, los únicos datos con los que se contaba para Puerta de Hierro eran los datos oficiales obtenidos del Censo Nacional de Hogares 2010, notas periodísticas y documentales que abordan la problemática de la venta y consumo de drogas en la villa. Se resaltan también trabajos realizados por instituciones académicas que han aportado documentos que recogen experiencias de familias que llegaron a la villa desde sus inicios. Los resultados que se presentan complementan y actualizan esta información, si bien con recursos limitados que supusieron la adaptación de la metodología a las posibilidades reales de acceso a la información. En relación con las condiciones de acceso al barrio y lo reducido del equipo de trabajo, se empleó una metodología no-probabilística para la selección de la muestra (bola de nieve). Se encuestó en su mayoría a las familias que acuden al comedor comunitario RENACER "Graciela" y al hogar de niños Santa Teresita Fundación CADENA. Hay limitaciones asociadas a este procedimiento, como la posibilidad de que algunos resultados puedan estar describiendo la situación de las familias más pobres dentro de la villa, y no necesariamente representan a la población total de Puerta de Hierro. El diagnóstico revela las condiciones de vida de los 50 hogares entrevistados. Por la forma en que fueron seleccionados los casos, pueden estar sesgados hacia las situaciones de mayor pobreza.

La información recabada presenta un cuadro de empeoramiento en las condiciones de vida respecto de los datos registrados en 2010, y coherente con los registros de estudios similares de índole cualitativa realizados en el barrio (García, 2015). Además de la gravedad de las carencias en cada una de las dimensiones analizadas, su análisis agregado permite determinar que casi la totalidad de los hogares relevados en Puerta de Hierro sufren privaciones en el espacio de los Derechos o en el de Bienestar. De hecho, más de la mitad de los hogares (64\%) presentan una situación de pobreza extrema, donde la indigencia de ingresos se agrega a la pobreza en el espacio de derechos.

Estos resultados ponen de manifiesto algunas consideraciones sobre Puerta de Hierro, que podrían hacerse extensivas a territorios similares del Conurbano Bonaerense. En primer lugar, se destaca la necesidad de disponer de información cuantitativa actualizada sobre las condiciones de vida de las personas que habitan en este barrio. Si bien se reconocen esfuerzos múltiples por registrar el fenómeno de la pobreza 
concentrada en villas y asentamientos -como la Plataforma Nacional del Hábitat, RENABAP y TECHO, entre otros-, estos esfuerzos ponen mayor atención en la localización de los barrios y sus dimensiones. En muchos casos, esta información está guiada por la voluntad de urbanización de estos barrios. Son necesarios diagnósticos centrados en la calidad de vida de las familias que habitan en villas y asentamientos para permitir a los hacedores de políticas públicas identificar las principales problemáticas que afrontan los habitantes de la villa, permaneciendo prácticamente invisibles. En Puerta de Hierro existen personas que trabajan y conocen las necesidades de los habitantes, organizaciones barriales, parroquiales, ONG que, con el financiamiento y el equipamiento técnico adecuado, podrían realizar estudios representativos que permitieran extender estos resultados al resto de la villa.

En este sentido, podemos utilizar los resultados de este estudio que, si bien limitado, permite elaborar ciertas sugerencias orientadas a la mejora de la población del barrio. En cuanto a la composición demográfica de Puerta de Hierro, se destacó que hay mayoría de población joven, donde el $70 \%$ son menores de 24 años. Estos datos ilustran el alto porcentaje de la población que está en edad productiva o lo estará en el futuro cercano, y quienes buscan abrirse espacios en el mercado laboral. Sin embargo, no cuentan con las herramientas que les permitan adherirse con éxito a los espacios laborales que cada vez son más escasos, dada su baja preparación. La descomposición de la pobreza muestra la mayor importancia de los déficits en dimensión educativa entre los hogares con pobreza extrema, y la disminución de la importancia de esta dimensión al considerarse los hogares en situación de pobreza (pobres, pero no indigentes, en el espacio de bienestar y pobres en el espacio de derechos). Se requiere entonces, que los jóvenes residentes de la villa tengan mayor acceso al sistema educativo, principalmente con el fin de hacer un empalme entre el secundario y la educación superior, por medio de un programa intermedio que los capacite para el trabajo, y donde los jóvenes puedan explotar todas sus habilidades en oficios que los preparen para el futuro. Se hace primordial que programas para la capacitación y orientación para el trabajo, como Jóvenes con Más y Mejor Trabajo ${ }^{35}$ se extienda a este tipo de poblaciones.

Si bien es cierto que, en muchos de los casos observados durante el trabajo de campo, los jóvenes manifestaron no ver la educación universitaria como una opción de vida, ya que sienten que sus familias no tienen los recursos económicos suficientes para sustentar estudios superiores, sí se mostraron muy interesados ante la posibilidad de acceder a algún tipo de programa que les permita valerse por sí mismos, ser autónomos en sus decisiones económicas, a través del aprendizaje de un oficio. En talleres realizados en la Fundación CADENA con chicos residentes de la villa en edades de 12 a 16 años por parte del programa de voluntariado internacional AIESEC ${ }^{36}$ (20152017), se observó un particular interés en el desarrollo de actividades como carpintería, mecánica, sistemas, cocina, asistencia social, primeros auxilios, etc.,

\footnotetext{
${ }^{35}$ Programa del gobierno Nacional Argentino que brinda a los jóvenes entre 18 y 24 años la oportunidad de hacer un entrenamiento laborar o generar su propio emprendimiento.

${ }^{36}$ AIESEC es un programa de voluntariado social internacional que reúne a jóvenes de diferentes nacionalidades. Los mencionados Talleres no forman parte de este estudio, sino que son actividades promovidas por la organización, para las cuales reciben formación del gobierno nacional (https://www.argentina.gob.ar/noticias/gjornada-de-concientizaci\%C3\%B3n-en-puerta-de-hierro).
} 
oficios de tipo técnico y tecnológico, que a futuro les pueden garantizar una fuente de ingresos para ellos y sus familias. Este tipo de oficios se convierte en una herramienta para que los jóvenes puedan superar su situación actual por sus propios medios, sin depender de la asistencia recibida, y permitiendo cortar la herencia transgeneracional de la pobreza, una "pobreza perpetua" (Giarrizo, 2013).

Las personas de la villa reclaman una presencia más permanente y continua del estado, que no solamente se evidencie mediante los mecanismos de asistencia a través de programas sociales (la Asignación Universal por Hijo y embarazo entre otros), y la presencia de la Gendarmería Nacional. Se requiere presencia del estado en cuanto al acceso de condiciones más básicas de vida, como el acceso al agua potable, al sistema de desechos de excretas y al gas natural, cuyos déficits profundos se pusieron en evidencia en este estudio. Pero, por sobre todo, se requiere de programas que generen movilidad social que les permitan a las familias, que llevan 5 décadas en situación de pobreza extrema, salir de su condición con esfuerzos propios, capacitándolos para que sean autónomos en la toma de decisiones que los lleve a superar su situación actual de "efecto túnel" (Hirschman y Rotschild, 1973) ${ }^{37}$. Puerta de Hierro requiere la creación de políticas relacionadas con las necesidades reales de la comunidad, políticas que permitan mejorar las condiciones de vida de las personas para que estas puedan alcanzar un ideal de vida satisfactorio.

37 "Cuando una persona pobre ve que la mayor parte de quienes están a su alrededor no tienen mejoras en su calidad de vida, se produce un desánimo provocado por la imposibilidad de tener esperanzas y por no ver la luz al final del túnel" (Jimenez, 2016). 


\section{Referencias}

Alkire, S. \& Foster, J. (2011). "Counting and Multidimensional Poverty measurement". Journal of Public Economics. 95 (7-8).

Alkire, S. \& Foster, J. (2007). "Choosing dimensions: the capability approach and multidimensional poverty". OPHI working Paper 88. Disponible en: https://mpra.ub.uni-muenchen.de/8862/1/MPRA_paper_8862.pdf

Alkire, S., Foster, J., Seth, S., Santos, M. E., Roche, J. M. \& Ballón, P. (2015). Multidimensional Poverty Measurement and Analysis. Oxford: Oxford University Press.

Arévalo, C. \& Paz, J. (2015). Pobreza en la Argentina. Privaciones múltiples y asimetrías regionales. Documento de Trabajo, IELDE.

Battiston, D., Cruces, G., López-Calva, L. F., Lugo, M. A. \& Santos, M. E. (2013). "Income and beyond: Multidimensional poverty in six Latin American countries". Social Indicators Research 112, 291-314. https://doi.org/10.1007/s11205-013-0249-3

Boltvinik, J. (2014). América latina de la vanguardia al rezago en medición Multidimensional de la pobreza. México: Colección CLACSO-CROP.

Bonfligio, J. I. (2015). Evaluación de la pobreza urbana desde un enfoque Multidimensional basado en derechos. Observatorio de la Deuda Social Argentina. Pontificia Universidad Católica Argentina.

CEPAL (2010). Aspectos normativos en pobreza Multidimensional, Curso técnico de Medición Multidimensional de la pobreza y sus aplicaciones. Comisión Económica para América Latina y el Caribe (CEPAL).

CEPAL (2013). Panorama Social de América Latina 2013. Santiago de Chile: Publicación de las Naciones Unidas. Disponible en: https://repositorio.cepal.org/bitstream/handle/11362/35904/S2013868_es.pdf?sequen $\mathrm{ce}=1$

CEPAL (2014). Panorama Social de América Latina 2014. Santiago de Chile: Publicación de las Naciones Unidas. Disponible en: https://repositorio.cepal.org/handle/11362/37626

Conconi, A. \& Ham, A. (2007). Pobreza Multidimensional Relativa. Una aplicación a Argentina. CEDLAS-UNLP.

CONEVAL (2009). Metodología para la medición multidimensional de la pobreza en México. Consejo Nacional de Evaluación de la Política de Desarrollo Social (CONEVAL).

Cravino, M. C. (org.) (2008). Los Mil barrios (in)formales. Aportes para la construcción de un Observatorio del hábitat popular del Área Metropolitana de Buenos Aires. Los Polvorines: Universidad Nacional de General Sarmiento.

Defensoría del Pueblo Ciudad Autónoma de Buenos Aires \& ODSA (2017). Caracterización de villas en la Ciudad de Buenos Aires. Aspectos sociodemográficos y habitacionales de los barrios villa 31, villa 31bis, villa 20 y Piletones. Disponible en: http://wadmin.uca.edu.ar/public/ckeditor/2017-Observatorio-Informes_Defensoria- 
CABA-24-10-VF.pdf

Defensoría del Pueblo Ciudad Autónoma de Buenos Aires (2010). Estudios sobre los procesos de integración social y urbana en tres villas porteñas. Buenos Aires: ODSA.

DEIE-UNICEF-IELDE (2019). Índice de Privaciones Múltiples. Nivel y Estructura de la Pobreza. Mendoza 2017-2018. Disponible en:

http://www.deie.mendoza.gov.ar/backend//uploads/files/2019-12-

20_15:00:56_Informe\%20Final\%20IPM\%20-

\%200ctubre\%202019\%20(\%C3\%9Altimo).pdf

Deneulin, S., Valencia, A. \& Clausen, J. (2018). Introducción al enfoque de las capacidades. Aporte para el Desarrollo Humano en América Latina. Buenos Aires: Manantial.

Departamento Nacional de Planeación República de Colombia (2011). Índice de Pobreza Multidimensional para Colombia (IPM-Colombia). Departamento Nacional de Planeación República de Colombia Archivos de Economía.

DGEyC (2019). Cuestionario de pobreza multidimensional. Encuesta Anual de Hogares 2019. Disponible en: https://www.estadisticaciudad.gob.ar/eyc/wpcontent/uploads/2015/04/2019_F_PMD_pobreza_multidimensional.pdf

DIGESTYC (2018). Encuesta de Hogares de Propósitos Múltiples 2017. Dirección General de Estadísticas y Censos del Ministerio de Economía del Gobierno de la República de El Salvador.

EDSA (2015). Encuesta de la Deuda Social Argentina. Pontificia Universidad Católica Argentina, Buenos Aires, Argentina: EDSA.

Eduardo, I. (1997). "Técnicas de medición económica". En Lora Torres, E. Técnicas de medición económica. Bogotá: Fedesarrollo.

Foster, J., Greer, J. \& Thorbecke, E. (1984). "A class of decomposable poverty measures". Econometrica, 52 (3), 761-766.

Gallo, D. (6 de septiembre de 2010). Pobreza y marginalidad/Menos argentinos se trasladan de las provincias al área metropolitana. Hay mayoría de extranjeros en las villas. La Nación, pág. 1.

Gallardo, M. (2020). "Measuring Vulnerability to Multidimensional Poverty". Social Indicators Research 148, 67-103. https://doi.org/10.1007/s11205-019-02192-y

García, M. (2015). El proceso de erradicación de villas. El caso de Puerta de Hierro en el partido de La Matanza. 1966-2013. II Jornada de Historia Reciente del Conurbano Bonaerense, paper 22 páginas. Disponible en:

http://observatorioconurbano.ungs.edu.ar/Articulos\%20y\%20documentos/1-marinaluz-garcia.pdf

Giarrizo, V. (2006). La pobreza subjetiva en Argentina. Construcción de indicadores para aproximarse al Bienestar de la Población (tesis doctoral). Facultad de Ciencias Económicas. Universidad de Buenos Aires (UBA), Buenos Aires, Argentina. 
González Quiroga, G. A. (2011). Análisis crítico de la medición de la pobreza una propuesta hacia la medición Multidimensional (tesis de maestría). Facultad de Ciencias Políticas y Relaciones Internacionales. Pontificia Universidad Javeriana, Bogotá, Colombia.

Hacienda, D. G. (2010). Situación y caracterización de los asentamientos precarios en la ciudad de Buenos Aires. Dirección General de Estadísticas y Censos Ministerio de Hacienda, 1-10.

Hirschman, A. O. \& Rotschild, M. (1973). "The changing tolerance for income inequality in the course of economic development". The Quarterly Journal of Economics, 87(4), 544-566. DOI: $10.2307 / 1882024$

INDEC (2010). Población total por sexo e índice de masculinidad. Provincia de Buenos Aires. Partido la Matanza. Instituto Nacional de Estadística y Censos (INDEC).

INDEC (2015). Encuesta Permanente de Hogares. Instituto Nacional de Estadística y Censos (INDEC).

INDEC (2017). Informes Técnicos Condiciones de Vida. Vol. 1, № 12. Buenos Aires: Publicaciones INDEC.

INDEC (2020). Incidencia de la pobreza y la indigencia en 31 aglomerados urbanos. Segundo semestre de 2019, Informes técnicos. Informes técnicos, Vol. 4, No 59. Condiciones de vida, Vol. 4, No 4. Instituto Nacional de Estadística y Censos (INDEC).

INEC (2015). Índice de Pobreza Multidimensional (IPM). Metodología. Instituto Nacional de Estadísticas y Censos de Costa Rica.

INEC (2017). Índice de Pobreza Multidimensional. Instituto Nacional de Estadísticas de Ecuador. Disponible en: https://www.ecuadorencifras.gob.ec/documentos/webinec/Sitios/Pobreza_Multidimensional/assets/infografia.pdf

Jiménez, M. (2016). La Movilidad Socioeconómica Intergeneracional en Argentina (tesis doctoral). Facultad de Ciencias Económicas. Universidad Nacional de La Plata. La Plata, Argentina. Disponible en:

http://www.depeco.econo.unlp.edu.ar/wp/wp-content/uploads/2017/09/tesisdoctorado-jimenez.pdf

Lépore, E. (coord.) Lépore, S., Mitchell, A., Macció, J. \& Rivero, E. (2012). Capacidades de desarrollo y sociedad civil en las villas de la ciudad [en línea]. Buenos Aires: Educa. Disponible en: http://bibliotecadigital.uca.edu.ar/repositorio/libros/capacidadessociedad-civil-villas.pdf

Lépore, E. \& Deneulin, S. (2020). Urban inequality and COVID-19 in Latin America. Centre for Development Studies. University of Bath. Disponible en: http://blogs.bath.ac.uk/cds/2020/05/27/urban-inequality-and-covid-19-in-latinamerica/

López, C. \& Safojan, R. (2013). "Un Análisis Multidimensional de la Pobreza: Evidencia Reciente de las Regiones de Argentina". Revista de Economía Política de Buenos Aires, 7 (12), 9-44. 
Macció, J. (2014). "Apéndice: Fuente de datos primarias del programa interdisciplinario sobre desarrollo humano e inclusión social", En Suárez, A. L., Mitchell, A. \& Lépore, E. (eds.). Las villas de la Ciudad de Buenos Aires: territorios frágiles de inclusión social [en línea]. Buenos Aires: Educa. Disponible en:

http://bibliotecadigital.uca.edu.ar/repositorio/libros/villas-ciudad-buenos-aires.pdf

Macció, J. \& Mitchell, A. (2018). Same city, worlds apart: multidimensional poverty and residential segregation in Buenos Aires. Ponencia presentada en Reunión Anual de la AAEP 2018. Disponible en: https://aaep.org.ar/anales/works/works2018/maccio.pdf

Marquez, J. B. (2010). Estudios sobre los procesos de integración social y urbana en tres villas porteñas. Defensoría del Pueblo Ciudad autónoma de Buenos Aires.

MEF (2017). Informe de Pobreza Multidimensional en Panamá 2017. Ministerio de Economía y Finanzas. Dirección de Análisis Económico y Social.

Ministerio de Desarrollo Social (2015). Informe sobre Desarrollo Social. Nueva metodología de medición de la pobreza en Chile. Ministerio de Desarrollo Social. Gobierno de Chile. Disponible en:

http://www.desarrollosocialyfamilia.gob.cl/pdf/upload/Libro_IDS_2015_final.pdf

Ministerio de Desarrollo Social (2019). Índice de Pobreza Multidimensional. IPM_Gt. Ministerio de Desarrollo Social de Guatemala. Disponible en: https://mppn.org/wpcontent/uploads/2019/10/Guatemala-Report-IPM-gt_29jul19-v1.1.pdf

Mitchell, A., Macció, J. \& Mariño Fages, D. (2019). "The Effects of Emergency Housing on Wellbeing: Evidence from Argentina's Informal Settlements". European Journal of Development Research 31, 504-529.

Mitchell, A. (2012). "Las organizaciones de la sociedad civil en las villas de Bajo Flores y de Barracas". En Lépore et al. Capacidades de desarrollo y sociedad civil en las villas de la ciudad [en línea]. Buenos Aires: Educa. Disponible en: http://bibliotecadigital.uca.edu.ar/repositorio/libros/capacidades-sociedad-civilvillas.pdf

Nusbaum, M. C. \& Sen, A. (compiladores) (1998). La Calidad de Vida . México : Fondo de la Cultura Económica.

ODSA (2017). Pobreza y desigualdad por ingresos en la Argentina urbana (2015). Tiempos de Balance. Observatorio de la Deuda Social Argentina, Doc. 29.

ODSA (2019). Pobreza Multidimensional Fundada en Derechos Económicos y Sociales Argentina Urbana (2018). Encuesta de la Deuda Social Argentina Serie Agenda para la Equidad.

ODSA (2020). La pobreza más allá de los ingresos: nuevo informe sobre pobreza multidimensional 2010-2019. Introducción de datos fundados en un Enfoque de Derechos. Documento de Trabajo. Disponible en:

http://wadmin.uca.edu.ar/public/ckeditor/Observatorio\%20Deuda\%20Social/Documen tos/2020/2020-OBSERVATORIO-DOCUMENTO-TRABAJO-NUEVO-INFORME-PM-

ENFOQUE-DERECHOS.pdf 
ODSA (26 de octubre de 2017). Los habitantes en villas miseria de Buenos Aires se quintuplican en 26 años. El País. Disponible en:

https://elpais.com/internacional/2017/10/26/argentina/1508985742_852129.html

Oficina del Alto comisionado de las Naciones Unidas para los Derechos Humanos. (2006). Preguntas frecuentes sobre el enfoque de Derechos Humanos en la cooperación para el Desarrollo. Oficina del Alto comisionado de las Naciones Unidas para los Derechos Humanos.

OPHI-PNUD (2020). Global Multidimensional Poverty Index 2020. Charting pathways out of multidimensional poverty. Disponible en URL: https://ophi.org.uk/wpcontent/uploads/G-MPI_Report_2020_Charting_Pathways.pdf

Paz, J. A. (2014). Pobreza multidimensional en la Argentina. Asimetrías regionales (Parte I). Documento de Trabajo. Instituto de Estudios Laborales y del Desarrollo Económico (ielde). Facultad de Ciencias Económicas, Jurídicas y Sociales. Universidad Nacional de Salta. Disponible en: https://www.aacademica.org/jorge.paz/51.pdf

Programa de las Naciones Unidas para el Desarrollo (2009). Aportes para el Desarrollo Humano en Argentina. Segregación Residencial en Argentina. Programa de las Naciones Unidas para el Desarrollo (PNUD).

RENABAP (2018). Relevamiento Nacional de Barrios Populares. Registro Nacional de Barrios Populares (RENEBAP).

Lucesole, M. J. \& Marina, R. (10 de marzo de 2015). A fondo. Puerta de Hierro: territorio abandonado y arrasado por el paco. La Nación, págs. 1-3.

Salvia, A., Tuñón, I. \& Poy, S. (2015). "Asignación Universal por Hijo para la protección social: impacto sobre el bienestar económico y el desarrollo humano de la infancia". Población y Sociedad, 22 (2), 101-134.

Santos, M. E. (2019). "Desafíos en el diseño de medidas de pobreza multidimensional". Serie Estudios Estadísticos. No. 100. Santiago, Comisión Económica para América Latina $y$ el Caribe (CEPAL) Disponible en : https://repositorio.cepal.org/handle/11362/44583

Santos, M. E. \& Villatoro, P. (2018). "A Multidimensional Poverty Index for Latin America". Review of Income and Wealth, 64 (1), 52-83. DOI: 10.1111/roiw.12275

Se dio inicio a la urbanización en Puerta de Hierro (12 de junio de 2017). Municipios de Argentina. Recuperado de:

https://www.municipiosdeargentina.com/noticias/2017/06/12/13705-se-dio-inicio-ala-urbanizacion-en-puerta-de-hierro

Sedronar (2017). Puerta de Hierro y San Petersburgo: Caracterización Sociodemográfica y Análisis Espacial de la Oferta de Servicios Públicos. Dirección de Análisis Territorial y Estadística, Dirección Nacional de Observatorio de Drogas.

Sen, A. (1985). Resources, Values and Development. Oxford: Basil Blackwell.

SIUBEN (2017). Índice de Pobreza Multidimensional de República Dominicana. Vicepresidencia de la República Dominicana y Sistema Único de Beneficiarios 
(SIUBEN). Disponible en: siuben.gob.do/wp-content/uploads/2019/07/libro-ipm-rd26062017.pdf

Sigue en pie la decisión de urbanizar Puerta de Hierro (5 de mayo de 2017). Diario NCO. Recuperado de: https://diario-nco.com/la-matanza/sigue-en-pie-la-decision-deurbanizar-puerta-de-hierro/

Suárez, A., Mitchell, A. \& Lépore. E. (eds.) (2014). Las villas de la Ciudad de Buenos Aires: territorios frágiles de inclusión social. Buenos Aires: Educa. Disponible en: http://bibliotecadigital.uca.edu.ar/repositorio/libros/villas-ciudad-buenos-aires.pdf

TECHO (2016). Relevamiento de Asentamientos Informales. TECHO, paper 316.

Tuñón, I. \& Poy, S. (2018). Barómetro de la Deuda Social de la Infancia. Informe de Avance 2018. La privación más urgente en la infancia: déficit alimentario y protección social. Disponible en:

http://wadmin.uca.edu.ar/public/ckeditor/Observatorio\%20Deuda\%20Social/Presentac iones\%202018/2018/2018-OBSERVATORIO-BDSI-INFORME-AVANCE-DEFICIT-

ALIMENTARIO.pdf

UNICEF (2018). Pobreza Monetaria y Privaciones No Monetarias en Argentina. Disponible en: https://www.unicef.org/argentina/media/4156/file/Pobreza\%20monetaria\%20y\%20pri vaciones\%20no\%20monetarias\%20en\%20Argentina.pdf

Villatoro, P. (2017). Presentación sobre la Medición Multidimensional de la pobreza en el marco del Taller "Uso de encuestas de hogares para la medición de los Objetivos de Desarrollo Sostenible sobre pobreza y desigualdad", Ciudad de Panamá, 10-11 agosto 2017. Disponible en URL: https://www.cepal.org/sites/default/files/presentations/0810-cepal-pobreza-multidimensional-pvillatoro.pdf

Zavaleta, D., Moreno, C. \& Santos, M. E. (2018). "La medición de la pobreza multidimensional en América Latina". En Deneulin, S., Clausen, J. \& Valencia, A. (eds) (2018) Introducción al Enfoque de las Capacidades. Aportes para el Desarrollo Humano en América Latina. p. 253-274. Buenos Aires: Manantial. 


\section{Apéndice metodológico - Análisis de robustez de la medida de pobreza multidimensional}

Durante la construcción de una medida de pobreza multidimensional, la selección de ponderaciones para las dimensiones y los indicadores dentro de cada dimensión, así como la elección del umbral de pobreza, son decisiones con cierta arbitrariedad y pueden tener un impacto en los resultados obtenidos. Por ese motivo, es conveniente presentar un análisis de robustez, que permita mostrar que las conclusiones del estudio no variarían significativamente de tomarse otras decisiones en la selección de ambos criterios.

En este apéndice se presentan dos análisis de robustez, siguiendo los lineamientos provistos por Alkire et. al (2015). En primer lugar, se analiza la robustez de los resultados a la estructura de ponderación elegida para la medida correspondiente al Espacio de Derechos. Para ello, se asigna de manera sucesiva un peso mayor a cada dimensión, distribuyendo igualitariamente el peso restante entre las demás dimensiones. Hacia adentro de cada dimensión, se distribuye igualitariamente el peso entre indicadores. En este caso, se optó por duplicar el peso $(40 \%)$ de una dimensión, mientras se ponderó cada una de las demás con un cuarto del $60 \%$ restante $(15 \%)$. Debido a que la medida está compuesta por 5 dimensiones, el procedimiento implica construir 5 medidas alternativas cuyos resultados se comparan con los de la medida original. En los gráficos que se presentan a continuación, la medida original calculada en este estudio se presenta como "Medida", en tanto que todas las alternativas se denominan "R_dimensión", identificándose la dimensión a la que se le otorgó mayor ponderación en ese caso. La Figura A1.a muestra el efecto del incremento en la ponderación de cada dimensión de la medida del espacio de Derechos sobre la medida multidimensional final, que combina este espacio con el de Bienestar. Se observan pocas variaciones en el resultado, dado que todas las alternativas presentan una mayoría de hogares en situación de pobreza extrema y proporciones similares del resto de las situaciones. En relación con lo observado al realizar la descomposición de la medida multidimensional para el espacio de Derechos, cuando se duplica el peso de la educación ( $R \_$edu) se observa una disminución del porcentaje de hogares en situación de pobreza, y en consecuencia, se incrementa la proporción de hogares vulnerables por ingresos.

El segundo análisis de robustez consiste en verificar las variaciones en los resultados ante cambios en el umbral seleccionado para la identificación de los pobres en el Espacio de Derechos. Este tipo de análisis es relevante cuando se busca determinar la dominancia de una distribución respecto de otra, cuando se comparan la pobreza de dos países o regiones, o bien de dos momentos del tiempo. En este caso, la naturaleza del estudio no nos permite realizar este tipo de comparaciones. Por ese motivo, optamos por hacer un análisis de robustez del umbral combinada con las distintas ponderaciones descriptas en el punto anterior. La Figura A1.b presenta el porcentaje de hogares en situación de pobreza $(\mathrm{H})$ en el Espacio de Derechos para cada uno de los umbrales posibles en la escala completa (tomados en intervalos de 10 puntos porcentuales), cuando se duplica secuencialmente el peso de cada dimensión. Se puede observar que las alternativas comienzan a presentar resultados más 
diferenciados recién para umbrales de $\mathrm{k}=40 \%$ o superiores y que, en esos casos, la medida calculada brinda resultados moderados (las medidas alternativas se encuentran por debajo y por encima de ésta).

Figura A1.a: Robustez de las ponderaciones utilizadas para la medida de pobreza en el Espacio de Derechos

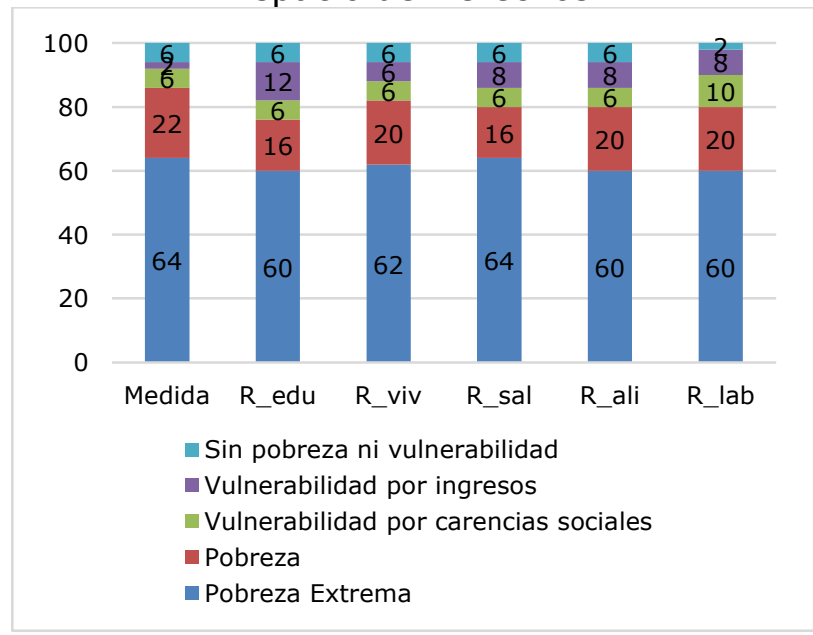

Fuente: Elaboración propia.
Figura A1.b: Robustez del umbral de pobreza en el Espacio de Derechos

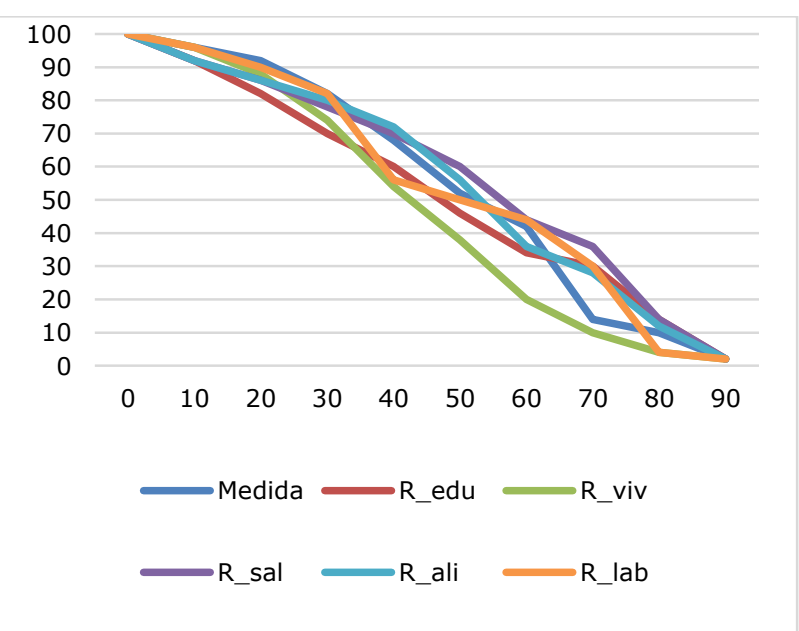

